\title{
CONSIDERACIONES SOBRE LA RELACIÓN ENTRE EL DERECHO A LA TUTELA JUDICIAL EFECTIVA Y LA MEDIACIÓN OBLIGATORIA*
}

\author{
Considerations on the relationship between the right to \\ effective judicial protection and the mandatory mediation
}

\author{
Pilar Peiteado Mariscal \\ Universidad Complutense de Madrid (España) \\ peiteado@der.ucm.es
}

http://dx.doi.org/10.18543/ed-66(2)-2018pp283-322

Recibido: 30.10 .2018

Aceptado: 21.11.2018

\section{Resumen}

Este trabajo versa sobre la relación entre la función jurisdiccional y los medios extrajudiciales de resolución de controversias. En concreto, examina el posible conflicto entre la mediación obligatoria, el derecho a la tutela judicial efectiva y otros principios y derechos que configuran nuestro sistema jurídico, prestando particular atención a los artículos 24.1 CE y 47 CDFUE y a la jurisprudencia del TC y del TJUE.

\section{Palabras clave}

Derecho a la tutela judicial efectiva; Mediación obligatoria.

* Cómo citar / Citation 'Chicago-Deusto' (Autor-fecha / Author-date / Lista de referencias / Reference list entries): Peiteado Mariscal, Pilar. 2018. «Consideraciones sobre la relación entre el derecho a la tutela judicial efectiva y la mediación obligatoria». Estudios de Deusto 66, n. ${ }^{\circ}$ 2: 283-322. http://dx.doi.org/10.18543/ed-66(2)-2018pp283-322.

Proyecto de Investigación «Administración pública y derechos fundamentales: nuevas perspectivas», DER2015-67695-C2-2-P (MINECO/FEDER). 


\section{Abstract}

This paper deals with the relationship between jurisdictional function and ADR. In particular, it focuses on potential conflicts between mandatory mediation, right to effective judicial protection and other principles and rights that draft our legal system. It pays particular attention to the articles $24.1 \mathrm{CE}$ and $47 \mathrm{CDFUE}$, and also to the TC and the ECJ jurisprudence.

\section{Keywords}

Effective judicial protection; Mandatory mediation. 


\begin{abstract}
Sumario: I. Situación de los términos del Debate. II. Premisa PREVIA. LA JURISDICCIÓN Y LOS MEDIOS ALTERNATIVOS DE RESOLUCIÓN DE CONFLICTOS NO SON CONCEPTUALMENTE EQUIVALENTES. III. EL DERECHO A LA TUTELA JUDICIAL EFECTIVA. 1. El derecho a la tutela judicial efectiva en la Constitución española. 2. En particular, derecho a la tutela judicial efectiva y derecho de acceso a los tribunales. 3. El derecho a la tutela judicial efectiva en la Carta de los Derechos Fundamentales de la Unión Europea. 4. Relación entre los artículos 24.1 de la Constitución y 47 de la Carta de los Derechos Fundamentales de la Unión Europea. IV. ¿VULNERA LA MEDIACIÓN OBLIGATORIA EL DERECHO A LA TUTELA JUDICIAL EFECTIVA? 1. Derechos fundamentales y autonomía de la voluntad. 2. Mediación obligatoria, acceso a los tribunales y tutela judicial efectiva. 3. La mediación obligatoria no vulnera el derecho a la tutela judicial efectiva, pero... V. CONCLUSIÓN. EL DERECHO A LA TUTELA JUDICIAL EFECTIVA NO ES EL ÚNICO PARÁMETRO QUE MIDE LA CONVENIENCIA DE UNA MEDIACIÓN OBLIGATORIA. BIBLIOGRAFÍA
\end{abstract}

\title{
I. SITUACIÓN DE LOS TÉRMINOS DEL DEBATE
}

En los últimos meses, varias resoluciones judiciales de muy distintas procedencia y calado han decidido cuestiones relacionadas con la posibilidad de que el acceso a los tribunales esté condicionado -o, incluso, sea sustituidopor el recurso a medios no jurisdiccionales de resolución de conflictos. Se trata de un conjunto de pronunciamientos realmente heterogéneo pero con varios puntos en común, entre los que se encuentran la reflexión sobre el alcance del derecho fundamental a la tutela judicial efectiva y sobre el papel que debe desempeñar el proceso judicial en relación con otras posibilidades de abordar la tutela de los derechos e intereses de los ciudadanos.

Este debate jurídico se produce en un contexto social determinado. No es este lugar en el que pueda hacerse un estudio muy profundo de una situación que tiene muchos perfiles distintos, ni soy tampoco una experta en las disciplinas propias del análisis de los fenómenos sociales. Sin embargo, creo que una observación atenta de la realidad permite definir al menos algunos parámetros, que pueden servir en ciertos casos para una mejor comprensión de lo que está sucediendo en el ámbito jurídico, y en otros, para formar criterio sobre lo que debe o puede suceder en el futuro.

A mi juicio, las cuestiones que son objeto de este trabajo se proyectan sobre un momento social/político/jurídico caracterizado -en lo que aquí nos interesa, y asumiendo la responsabilidad por la distorsión que la evidente simplificación pueda causar en el enfoque- por dos conjuntos de factores, que pueden agruparse en torno a las etiquetas de cualitativos y cuantitativos. Los 
factores cualitativos aluden, sobre todo, a dos cuestiones. La primera es la relación entre los ciudadanos y las instituciones que configuran el Estado o las entidades supraestatales. En décadas anteriores, esta relación estaba marcada por la distancia que se desprendía tanto de la auctoritas y de la potestas que emanaban de ellas como de la lejanía que genera el desconocimiento. Esta distancia tenía una lectura con un sesgo más positivo, que puede traducirse como respeto o reconocimiento de una posición de supremacía; pero se entrevén también en ella factores menos amables, como una escasa implicación de los ciudadanos en los asuntos públicos o el protagonismo de una élite social e intelectual reducida.

Actualmente esa lejanía ha desaparecido, porque el desconocimiento ha sido sustituido por el conocimiento, o al menos por la abundancia de datos y de información. En ocasiones se trata de un conocimiento profundo y riguroso, que origina la formación de grupos sociales comprometidos, informados y exigentes; así ha sucedido en el sector social y en determinados ámbitos de las relaciones laborales, económicas y de consumo. En otras, se trata de un conocimiento que responde al fenómeno de la vulgarización, es decir, un conocimiento muy extendido y muy presente en la vida social, pero también muy superficial, que atiende poco a las causas y fundamentos profundos de lo que sucede; la consecuencia de este tipo de conocimiento es la formación de grupos sociales conscientes de los derechos anudados a la posición de ciudadano pero menos de los deberes que también conlleva, y que juzgan las instituciones con dureza extrema, porque la superficialidad o el conocimiento parcial facilitan la polaridad y la idea de que todo lo que no es sencillo, fácil $\mathrm{y}$ rápido responde a intereses ocultos y nocivos. Este tipo de conocimiento genera desafección, porque conduce fácilmente - pero falsamente también- a pensar que todo funciona mal y que es sencillo hacerlo mejor, de modo que esa supuesta maldad cae sobre quienes integran las instituciones del Estado.

Es este modo de conocimiento el que se ha propagado con frecuencia respecto del Derecho y de la Administración de Justicia. Nunca se oyó tanto hablar de instituciones y conceptos jurídicos en el espacio público como ahora, pero, con frecuencia, esto no conduce a una mayor formación de los ciudadanos sino a una de-formación de la opinión pública en asuntos que tienen que ver con la Justicia. Esta deformación se convierte en presión sobre los tribunales. En una presión que proviene de los ciudadanos, que no comprenden el ritmo ni el sentido de las resoluciones judiciales, y en una presión que proviene también de otros poderes públicos, que ven en el cuestionamiento del sistema de Justicia un modo -irresponsable- de acercarse a la opinión pública.

Otro grupo de factores que hay que tener en cuenta en el momento de examinar cuestiones relacionadas con el sistema de Justicia son los cuantitativos. No podemos ignorar, por un lado, que la complejidad de las relaciones 
personales y económicas propia de nuestras sociedades determina que tanto el número y dificultad de las normas que las rigen como la litigiosidad que generan se incrementan respecto de lo que vieron épocas pasadas. Esta elevada demanda de resolución de conflictos frente al Estado desdibuja a veces las fronteras entre el ciudadano y el consumidor, entre quien se mueve en un espacio público y quien lo hace en otro estrictamente privado; y con ello también las líneas divisorias entre lo que se puede exigir y pretender en cada caso. Y, por otro lado, los últimos años han recordado a los Estados occidentales, en su mayoría Estados sociales o Estados del bienestar, que los recursos económicos no son ilimitados, y que las decisiones sobre asignación de los recursos son máximamente relevantes para el mantenimiento de las estructuras sociales y políticas que hasta ahora nos han sostenido.

Los factores cuantitativos y cualitativos a los que me he referido forman parte habitual de la fundamentación de las posiciones relacionadas con las materias de que se va a tratar aquí. Sin embargo, y como se verá, a veces no son explícitos, o se otorga una vestidura jurídica a lo que tiene un fundamento económico, político o que reside en la opinión pública.

\section{PREMISA PREVIA. LA JURISDICCIÓN Y LOS MEDIOS ALTERNATIVOS DE RESOLUCIÓN DE CONFLICTOS NO SON CONCEPTUALMENTE EQUIVALENTES}

Con la expresión «medios alternativos de resolución de conflictos»se alude comúnmente a sistemas heterocompositivos o autocompositivos a los que los particulares pueden recurrir para solucionar controversias, en lugar de incoar un proceso ante los tribunales que resulten competentes ${ }^{1}$. Sin embargo, y pese a que la expresión es suficientemente descriptiva y está completamente extendida ${ }^{2}$, creo necesario precisar que esa alternatividad respecto de la jurisdicción se puede predicar solo de la resolución de conflictos, que es todo el objeto y contenido de estos medios pero no es todo el objeto y contenido de la jurisdicción. La jurisdicción no se comprende solo como un medio de solución de conflictos, es algo más. No es sencillo definir

${ }^{1}$ El núcleo central de los conocidos como ADR o MARC se estructura en torno al arbitraje, la mediación y la negociación, que tienen caracteres específicos y bien diferenciados. A su alrededor ellos se agrupan otras modalidades, tradicionales como la conciliación o más recientes, como el med arb o el arb med. La realidad es que no están reglados ni constituyen un sistema numerus clausus definido en ningún sitio, de modo que cualquier sistema de composición ajeno a los tribunales puede ser incluido en esta categoría.

2 También se van abriendo paso otras que no ponen el acento en la idea de alternatividad sino en la de complementariedad. Vid. Iglesias Buhígues y Calderón Cuadrado 2011, 8-15 y 28-29. 
ese más, ese plus, ese algo que es solo específico de la función jurisdiccional. Siguiendo a De la Oliva ${ }^{3}$, que enseña que lo propio de la función jurisdiccional es tutelar el Derecho objetivo, decir el Derecho al caso concreto, considero que lo que caracteriza a la jurisdicción es que su existencia y su función se justifican a su vez por la existencia de la norma, del Derecho; la jurisdicción existe para que el Derecho alcance el lugar que le corresponde en el modelo de Estado en el que vivimos, para afirmar su primacía por encima de las actuaciones de los poderes públicos y su carácter de esencial elemento rector de las relaciones de todo tipo entre los ciudadanos y entre éstos y los poderes públicos.

Las resoluciones de la jurisdicción pueden pronunciarse en supuestos de conflicto y en otros supuestos; y siempre, aun resolviendo el caso concreto, aspiran a la validez general, porque interpretan y aplican la norma, que es general y tiene vocación de permanencia; las resoluciones de la jurisdicción tienen potencia explicativa sobre el modo en que se producen y comprenden las relaciones sociales en el seno de un determinado grupo humano. Los medios alternativos de resolución de conflictos justifican su existencia, por el contrario, en el conflicto, que es siempre concreto y pasajero, y no pueden alcanzar la generalidad de la norma, que no es su punto central de referencia, ni acercarse al papel que a ésta le corresponde desempeñar en la construcción y consistencia de la sociedad y del Estado. Por eso, jurisdicción y medios alternativos de resolución de conflictos no constituyen los dos miembros de una igualdad: existe entre ambas proposiciones un desequilibrio de peso, por decirlo gráficamente, ya que la jurisdicción comprende la resolución de conflictos y algo más, tiene una posición primordial para la existencia y prevalencia de la norma jurídica, que es el último garante de la libertad y de los derechos de cada uno de los ciudadanos en un Estado de Derecho.

Resolver conflictos no es exactamente lo mismo que hacer Justicia. En uno y otro caso el horizonte coincide, la paz social, pero es distinto el modo de alcanzarla. La resolución extrajurisdiccional de conflictos puede encontrar apoyo en cualquier criterio, llega a la paz social por muchos caminos. En cambio, la solución jurisdiccional solo puede fundarse en la norma jurídica, en la norma que es aplicada, además, por unos órganos que reúnen unos caracteres específicos; llega a la paz social a través de la Justicia. Es cierto que este modo positivista de presentar la Justicia es muy imperfecto, pero no pretendo trasladar ahora una visión personal y completa sino fijar algunos trazos que resultan necesarios. En un Estado Social de Derecho, la creación de la norma jurídica sigue unos cauces que la acercan a la voluntad popular, $\mathrm{y}$, en cuanto a su contenido, se engarza en un sistema jurídico que busca

\footnotetext{
3 De la Oliva Santos 2016, 17-19.
} 
asegurar que, viviendo en colectividad, la libertad y los derechos individuales queden salvaguardados y sea posible una cierta protección para las minorías y los más débiles. Quiere decirse con esto que la administración de Justicia, lejos de la visión que en ocasiones la vincula al autoritarismo, a la imposición y a una sociedad absolutista y no participativa ${ }^{4}$, forma parte de los elementos que constituyen la esencia de los Estados modernos. Y, todavía hoy, su incapacidad para asumir las funciones que le corresponden o su debilidad extrema determina la consideración de un Estado como fallido, con las graves consecuencias de todo tipo que estas situaciones acarrean para las personas. La aspiración a la Justicia, a que en nombre del Estado se haga Justicia, es irrenunciable para los Estados de Derecho.

Todo lo anterior no significa que no pueda haber otros medios de resolución de controversias; al contrario, la idea del sistema de Justicia multirooms ${ }^{5}$ me parece interesante y atractiva, pero en el bien entendido de que no todas las rooms son iguales, ni el nivel de implicación del Estado en ellas puede ser el mismo, ni los derechos básicos del justiciable se satisfacen con el acceso a cualquier room. Tal vez lo menos acertado sea el nombre, porque Justicia, realmente Justicia, en el sentido en el que la tradición jurídica continental la entiende $-y$ pienso que hay más peligros que ventajas en diluir este concepto, especialmente, como siempre, para quienes más tienen que perder-, solo está asegurada en la habitación en la que se produce el ejercicio de la función jurisdiccional ${ }^{6}$. Creo que situar las cosas en su justo punto de partida ayuda a la claridad de los análisis posteriores.

\section{EL DERECHO A LA TUTELA JUDICIAL EFECTIVA}

\section{El derecho a la tutela judicial efectiva en la Constitución española}

La definición básica del derecho a la tutela judicial efectiva en el ámbito de nuestro ordenamiento jurídico se construye desde los primeros pronunciamientos del Tribunal Constitucional sobre este derecho fundamental y, aunque ha sido muy desarrollada y precisada a causa de los muchos recursos de amparo que alegan su vulneración y de las incontables ocasiones en las que, como consecuencia, el Tribunal Constitucional ha tenido que volver sobre su contenido y caracteres, sus perfiles permanecen estables ${ }^{7}$. El derecho funda-

4 Ortuño Muñoz 2017, 52-53.

5 Barona Vilar 2016, 51-56; especialmente estas páginas en este punto, pero el artículo completo es de gran interés.

${ }^{6}$ Volveré sobre este punto en el epígrafe 5.

7 Todos los manuales de Derecho Procesal, imagino que también los de Derecho Constitucional, incontables obras monográficas y la gran mayoría de las sentencias del 
mental de todas las personas a obtener la tutela efectiva de los jueces y tribunales en el ejercicio de sus derechos e intereses legítimos (artículo 24.1 CE) es considerado por el Tribunal Constitucional como un haz o conjunto de derechos, que tienen su núcleo en lo que la doctrina procesal conoce como «derecho al proceso», es decir, el derecho a obtener una resolución sobre el fondo del asunto que haya sido sometido a los tribunales, siempre que, por un lado, concurran los presupuestos establecidos por el legislador para ello y, por otro -y en sentido contrario-, no esté presente ningún obstáculo u óbice que impida que tal pronunciamiento sobre el fondo se produzca. El derecho a la tutela judicial efectiva es, pues, un derecho de configuración legal, que no se ejercita directamente sobre la base del texto constitucional, sino dentro del marco establecido por el legislador ordinario ${ }^{8}$.

Tanto los presupuestos como los óbices que condicionan en sentido positivo y negativo la resolución sobre el fondo del asunto en la que el núcleo del derecho consiste, son de naturaleza procesal, y esto tiene dos implicaciones. La primera, que está en manos de quien se dirige a los tribunales cumplir con estas exigencias de carácter procesal (formulando su demanda ante tribunal competente, o solicitando tutela respecto de un asunto que no ha sido ya resuelto anteriormente o que no se encuentra pendiente de resolución, por poner ejemplos de presupuestos y óbices, respectivamente), generando así en el órgano jurisdiccional la obligación de resolver el fondo del asunto. La segunda, que no están vinculados al sentido en que se resuelve el fondo ni prejuzgan o presuponen nada sobre él, porque no pertenecen al ámbito material, de modo que tanto satisface el derecho a la tutela judicial efectiva la resolución sobre el fondo del asunto

Tribunal Constitucional que resuelven recursos de amparo sobre el artículo 24.1 de la Constitución ofrecen una definición del contenido del derecho a la tutela judicial efectiva, incidiendo, según las circunstancias, en el conjunto o en alguno de sus aspectos parciales. La descripción de lo que puede entenderse por este derecho fundamental que enuncio a continuación no pretende tanto constituir una definición original y personal como formular un concepto conciso y completo que sirva de referencia para el desarrollo posterior de este trabajo. Los fundamentos de mi formación y pensamiento en lo que se refiere a la posición de los ciudadanos respecto de la administración de Justicia-que es una cuestión previa al derecho fundamental, y necesaria para tener criterio sobre el modelo de administración de Justicia y de proceso que se quiere- se los debo al magisterio de Andrés de la Oliva, expuesto sobre esta materia de forma monográfica y completa en De la Oliva Santos, 1980 .

${ }^{8}$ La doctrina recuerda que las resoluciones iniciales del Tribunal Constitucional sobre el derecho a la tutela judicial efectiva resaltaban más la idea de que, si bien el legislador configura los cauces procesales de acceso a los tribunales, el derecho emana directamente de la Constitución y debe ser respetado en su contenido esencial. En este sentido Borrajo Iniesta, Díez-Picazo Giménez y Fernández Farreres 1995, 42. 
que estima la pretensión del demandante como la que la rechaza, absolviendo al demandado?

Como ya se ha dicho, el contenido del derecho a la tutela judicial efectiva es multiforme o plural, puesto que el derecho a obtener una resolución sobre el fondo del asunto se vincula a otros derechos, como causa o consecuencia de ellos. Así, el derecho a la tutela judicial efectiva ampara el derecho de acceso a los tribunales (vid. infra epígrafe 3.2), que se entiende inherente al derecho a obtener una resolución sobre el fondo del asunto; se extiende a los caracteres de esta resolución, porque no cualquier pronunciamiento sobre el fondo satisface el derecho a la tutela judicial efectiva sino solo el que es exhaustivo y congruente y se funda en una motivación que no es arbitraria o irracional; y alcanza a ámbitos procesales distintos de la obtención de una resolución sobre el fondo pero íntimamente conectados con los conceptos de «tutela judicial»y de «efectividad», de manera que el derecho a la tutela judicial efectiva se encuentra también integrado por el derecho a los recursos, a la ejecución de las resoluciones judiciales en sus propios términos y a la tutela cautelar, todo ello con el contenido y alcance definidos por el Tribunal Constitucional.

\section{En particular, derecho a la tutela judicial efectiva y derecho de acceso a los tribunales}

La faceta del derecho a la tutela judicial efectiva que en mayor medida puede ser desconocida o vulnerada con la imposición obligatoria del recurso a medios de resolución de conflictos distintos de la jurisdicción es el derecho de acceso a los tribunales. Tradicionalmente, éste se ha entendido fundamentalmente como un mandato dirigido primeramente al legislador, que no puede promulgar normas que excluyan la posibilidad de que los tribunales se pronuncien sobre ningún sujeto (vertiente subjetiva del derecho de acceso a los tribunales) ni sobre ninguna materia (vertiente objetiva del derecho de acceso a los tribunales). En este sentido, o desde esta perspectiva, se trata de un derecho incondicionado y no sujeto a configuración legal: no hay ninguna situación que permita legítimamente que el legislador sitúe personas o asuntos completamente fuera del alcance de la jurisdicción. En palabras de la STC 37/1995, de 7 de febrero, «El derecho a poder dirigirse a un Juez en busca de protección para hacer valer el derecho de cada quien, tiene naturaleza constitucional por nacer directamente

${ }^{9}$ El ámbito material está vinculado al derecho de acción o derecho a obtener una sentencia favorable, derecho excluido desde los primeros pronunciamientos del Tribunal Constitucional -por razones prácticas y evidentes- del ámbito del derecho fundamental a la tutela judicial efectiva. De la Oliva 1996, 25-31. 
de la propia Ley suprema» ${ }^{10}$. O de Díez-Picazo, «todo derecho o interés legítimo -es decir, cualquier situación jurídicamente relevante- debe poder hacerse valer, llegado el caso, en un proceso ante un verdadero órgano judicial, quedando constitucionalmente prohibida toda forma de denegación de justicia» ${ }^{11}$.

No es común, sin embargo, encontrar formulaciones tajantes y claras de este punto, siendo frecuente la presentación conjunta de todos los aspectos del derecho a la tutela judicial efectiva. Incluso aunque se distinga nominalmente el derecho de acceso a los tribunales, no se separa conceptualmente después de la obtención de una resolución sobre el fondo del asunto, con la consecuencia de que todo queda definido como un derecho prestacional y de configuración legal cuando, afortunadamente, esto no es exacto. Y digo afortunadamente porque considero que no queda en manos del legislador ordinario (como sucedería si el acceso a los tribunales se tratase de un derecho de configuración legal) definir sobre qué asuntos tenemos derecho a obtener una resolución sobre el fondo. Nuestro derecho a ser tutelados por la jurisdicción se extiende a cualquier asunto, y toda limitación sobre este punto es inconstitucional. Después, la tutela a la que tenemos derecho consiste en obtener una resolución sobre el fondo del asunto, y las condiciones en que esta resolución puede producirse en cada caso concreto sí dependen de la configuración hecha por el legislador ordinario. Pero no la posibilidad en abstracto de dirigirse a los tribunales sometiéndoles el asunto, cualquier tipo de asunto.

En ocasiones, la falta de nitidez al deslindar los distintos planos del derecho a la tutela judicial efectiva alcanza a la propia jurisprudencia constitucional. La STC 6/2018, de 22 de enero (ECLI:ES:TC:2018:6) -por lo demás, muy interesante y bien fundada-, aborda juntos y bajo la denominación «derecho de acceso a la jurisdicción» tanto el acceso a los tribunales propiamente dicho como el derecho a una resolución sobre el fondo: «El primer contenido del derecho que reconoce el artículo $24.1 \mathrm{CE}$ es el acceso a la jurisdicción, que permite ser parte en un proceso y obtener un pronunciamiento sobre las pretensiones deducidas. No se trata, sin embargo, de un derecho absoluto e incondicionado, sino que ha de someterse a los cauces procesales existentes y de acuerdo con la ordenación legal pues, en cuanto derecho de configuración legal, su ejercicio y dispensación se supeditan al cumplimiento de los presupuestos y requisitos establecidos

${ }^{10}$ La sentencia, que resuelve un amparo contra la inadmisión de un recurso de casación, establece una distinción nítida entre el derecho de acceso a los tribunales y el derecho a los recursos, que es también una faceta del derecho a la tutela judicial efectiva y continúa diciendo: «En cambio, que se revise la respuesta judicial, meollo de la tutela, que muy bien pudiera agotarse en sí misma, es un derecho cuya configuración se defiere a las leyes. Son, por tanto, cualitativa y cuantitativamente distintos».

11 Díez-Picazo Giménez 2013, Capítulo XV del libro en formato electrónico. 
por el legislador en cada caso. Por tal razón, queda también satisfecho cuando se emite un pronunciamiento de inadmisión que aprecie razonada y razonablemente la concurrencia de una causa establecida expresamente en la ley».

En cambio, y curiosamente, una de las expresiones más claras en este sentido se contienen en la STC 58/2016, de 17 de marzo, que no menciona expresamente el derecho de acceso a la jurisdicción sino que se refiere directamente a la tutela judicial efectiva, aunque es evidente que el núcleo del asunto reside en este primer nivel del derecho, puesto que la cuestión de inconstitucionalidad se suscita respecto de determinadas resoluciones del secretario judicial que son irrecurribles, de modo que su objeto no se plantea nunca ante los verdaderos titulares de la potestad jurisdiccional, los jueces y magistrados. «El derecho fundamental garantizado por el art. 24.1 CE comporta que la tutela de los derechos e intereses legítimos de los justiciables sea dispensada por los Jueces y Tribunales, a quienes está constitucionalmente reservada en exclusividad el ejercicio de la potestad jurisdiccional (art. 117.3 CE). Este axioma veda que el legislador excluya de manera absoluta e incondicionada la posibilidad de recurso judicial contra los decretos de los Letrados de la Administración de Justicia resolutorios de la reposición, como acontece en el cuestionado párrafo primero del art. 102 bis.2 LJCA». Continúa el TC: «Entenderlo de otro modo supondría admitir la existencia de un sector de inmunidad jurisdiccional, lo que no se compadece con el derecho a la tutela judicial efectiva (...) y conduce a privar al justiciable de su derecho a que la decisión procesal del Letrado de la Administración de Justicia sea examinada y revisada por quien está investido de jurisdicción (esto es, por el Juez o Tribunal), lo que constituiría una patente violación del derecho a la tutela judicial efectiva».

Este contenido tan de primer nivel del derecho a la tutela judicial efectiva, la necesidad de que nada quede excluido del acceso a la jurisdicción, sirve como parámetro de constitucionalidad de la actuación del legislador, como ya se ha dicho, pero también de la propia de los tribunales, de modo que lo que sería inconstitucional de iure (establecer exclusiones subjetivas u objetivas del acceso a los tribunales) lo es también si se produce de facto, bien porque las normas que regulan los cauces de acceso a los tribunales dificultan este acceso extraordinariamente, bien porque -como suele suceder con mayor frecuencia- los tribunales las interpretan al aplicarlas en un sentido obstaculizador del acceso de los ciudadanos a la jurisdicción ${ }^{12}$. Así, la ya

${ }_{12}$ Es cierto que la interposición y estimación de recursos de amparo respecto de la vulneración del derecho a la tutela judicial efectiva en su vertiente de acceso a la jurisdicción es más frecuente que el planteamiento y estimación de cuestiones de inconstitucionalidad por este motivo. Sin embargo, no faltan los ejemplos, como puede verse en las recientes y relevantes SSTC 140/2016, de 21 de julio, que declara la nulidad de determinados preceptos de la Ley de tasas en el ámbito de la administración de Justicia, y 1/2018, de 11 
citada STC 6/2018, de 22 de enero (ECLI:ES:TC:2018:6), se refiere a dos circunstancias que pueden determinar la vulneración del derecho a la tutela judicial efectiva en su vertiente de acceso a los tribunales. Por un lado, conculcan el derecho fundamental las resoluciones de inadmisión que puedan estimarse arbitrarias, irrazonables o patentemente erradas; $y$, por otro, las que se basan en criterios que, por su rigorismo, formalismo excesivo o cualquier otra razón, «revelen una clara desproporción entre los fines que la causa legal aplicada preserva y los intereses que se sacrifican como consecuencia de la inadmisión».

Esta resolución, que se trae aquí porque, siendo de fecha reciente, recoge con claridad la doctrina constitucional sobre el derecho de acceso a los tribunales, expone también los matices con los que -desde hace ya años, y después de una época de afirmación más rotunda- el Tribunal Constitucional acompaña la explicación y aplicación del conocido como principio pro actione: los tribunales deben aplicar las normas que regulan el acceso a la jurisdicción teniendo en cuenta su sentido y finalidad, pero esto no significa que solo sea constitucional la interpretación más favorable a la admisión de la demanda o acto procesal de que se trate. La STC 6/2018, de 22 de enero, supone igualmente un claro ejemplo del contenido que el TC atribuye a la circunstancia de «error patente» en la inadmisión de la acción que se pretende ejercitar ante los tribunales y cuya concurrencia determina el otorgamiento del amparo. Como ejemplos, también recientes, de las restantes circunstancias que el Tribunal Constitucional considera determinantes de la vulneración del derecho a la tutela judicial efectiva en su vertiente de acceso a los tribunales pueden verse las SSTC 4/2017, de 16 de enero (ECLI:ES:TC:2017:4), respecto de la interpretación irrazonable de los requisitos establecidos por el legislador; 222/2016, de 19 de diciembre de 2016, respecto de la desproporción en la aplicación de las normas de acceso; 39/2015, de 2 de marzo, que aprecia excesivo rigor y formalismo en la interpretación de la norma procesal; y 115/2015, de 8 de junio de 2015, que considera arbitraria e irrazonable la decisión de inadmisión de una demanda a causa de la carencia de un requisito no exigido por la norma procesal.

De lo que se ha dicho hasta ahora se desprende que el acceso a los tribunales tiene que ser posible para todo tipo de sujetos y asuntos, de modo que la tutela de este derecho implica vigilar y garantizar que no se impide por vías directas o indirectas; pero esto no significa que el acceso a la jurisdicción tenga que ser inmediato, y tampoco incondicionado. Todos los derechos fundamentales pueden entrar en concurrencia con otros derechos o intereses de rango constitucional y es necesario, entonces, limitarlos, en la medida en que

de enero (ECLI:ES:TC:2018:1), que estima igualmente nula por afectación del derecho a la tutela judicial efectiva una norma de la Ley de Contrato de Seguro. 
lo indique un juicio de proporcionalidad. Como se verá en el epígrafe siguiente, ésta es la perspectiva desde la que el TJUE comienza a abordar la posible introducción de procedimientos obligatorios previos al ejercicio de acciones ante los tribunales.

\section{El derecho a la tutela judicial efectiva en la Carta de los Derechos Fundamentales de la Unión Europea}

La Carta de los Derechos Fundamentales de la Unión Europea (CDFUE), que vincula a los Estados miembros en virtud del artículo 6 del Tratado de la Unión Europea ${ }^{13}$, rotula el artículo 47 como «Derecho a la tutela judicial efectiva y a un juez imparcial», y establece en su primer párrafo que «Toda persona cuyos derechos y libertades garantizados por el Derecho de la Unión hayan sido violados tiene derecho a la tutela judicial efectiva respetando las condiciones establecidas en el presente artículo» ${ }^{14}$.

La razón por la que me detengo en el artículo 47 CDFUE y no en otras normas equivalentes de Tratados equivalentes es doble. Por un lado, de entre todos los textos internacionales que contienen proclamaciones de derechos vinculantes para nuestro país, la Carta es el único que utiliza los términos «tutela judicial efectiva». En efecto, la referencia a la tutela judicial efectiva no aparece en las normas que podrían considerarse correlativas de la Declaración Universal de Derechos Humanos, ni del Pacto de Derechos Civiles y Políticos ni del Convenio Europeo para la Protección de los Derechos Humanos y las Libertades Fundamentales. Por otro lado, las resoluciones que actualmente se pronuncian sobre la relación entre medios extrajudiciales de resolución de conflictos y derecho a la tutela judicial efectiva provienen del TJUE, sobre la base del artículo 47 CDFUE.

Para comprender el contenido que el legislador europeo atribuye al derecho a la tutela judicial efectiva resulta particularmente iluminadora la justificación del conjunto de la norma que se recoge en las Explicaciones sobre la Carta de los Derechos Fundamentales elaboradas y publicadas ${ }^{15}$ por la

${ }^{13}$ Con las particularidades respecto del Reino Unido y de Polonia que se contienen en el Protocolo $n^{\mathbf{0}} 30$ de la Carta.

${ }^{14} \mathrm{El}$ segundo párrafo del artículo 47 establece que «Toda persona tiene derecho a que su causa sea oída equitativa y públicamente y dentro de un plazo razonable por un juez independiente e imparcial, establecido previamente por la ley. Toda persona podrá hacerse aconsejar, defender y representar». Y el párrafo tercero, que «Se prestará asistencia jurídica gratuita a quienes no dispongan de recursos suficientes siempre y cuando dicha asistencia sea necesaria para garantizar la efectividad del acceso a la justicia».

15 En el mismo Diario Oficial de la Unión Europea en el que se publica la Carta, de 14 de diciembre de 2007, C 303. 
Convención que redactó la Carta; como las mismas Explicaciones manifiestan, «si bien no tienen por sí mismas valor jurídico, constituyen un valioso instrumento de interpretación con objeto de aclarar las disposiciones de la Carta». Pues bien. Frente a los que es común leer u oír-también respecto de nuestro artículo 24.1 CE-, las Explicaciones no identifican el inciso primero del artículo 47 con el artículo 6 del Convenio Europeo de Derechos Humanos $(\mathrm{CEDH})$, sino con el artículo 13 de este texto legal, que dispone que «Toda persona cuyos derechos y libertades reconocidos en el presente Convenio hayan sido violados tiene derecho a la concesión de un recurso efectivo ante una instancia nacional, incluso cuando la violación haya sido cometida por personas que actúen en el ejercicio de sus funciones oficiales». Las Explicaciones consideran que el artículo 47 de la Carta amplía el ámbito del artículo 13 del Convenio y mejora la protección de los derechos que este ofrece, puesto que garantiza que el ejercicio de cualquier derecho puede realizarse, no ante cualquier instancia, sino ante un juez.

La intención del legislador europeo de la CDFUE se clarifica del todo cuando las Explicaciones se refieren al segundo inciso del artículo 47: «Toda persona tiene derecho a que su causa sea oída equitativa y públicamente y dentro de un plazo razonable por un juez independiente e imparcial, establecido previamente por la ley. Toda persona podrá hacerse aconsejar, defender y representar». Como es evidente, este inciso sí está basado en el artículo 6.1 del $\mathrm{CEDH}^{16}$; y esta norma refiere el derecho a que una causa sea oída equitativa, públicamente y en un plazo razonable por un tribunal independiente e imparcial a «los litigios sobre sus derechos y obligaciones de carácter civil o sobre el fundamento de cualquier acusación en materia penal». Como consecuencia, las Explicaciones, en el comentario al inciso segundo del artículo 47 CDFUE señalan que «en el Derecho de la Unión, el derecho a un tribunal no se aplica únicamente a litigios relativos a derechos y obligaciones de carácter civil. Es una de las consecuencias del hecho de que la Unión sea una comunidad de Derecho (...) No obstante, salvo en lo referente a su ámbito de

${ }^{16}$ «Toda persona tiene derecho a que su causa sea oída equitativa, públicamente y dentro de un plazo razonable, por un Tribunal independiente e imparcial, establecido por la Ley, que decidirá los litigios sobre sus derechos y obligaciones de carácter civil o sobre el fundamento de cualquier acusación en materia penal dirigida contra ella. La sentencia debe ser pronunciada públicamente, pero el acceso a la Sala de Audiencia puede ser prohibido a la prensa y al público durante la totalidad o parte del proceso en interés de la moralidad, del orden público o de la seguridad nacional en una sociedad democrática, cuando los intereses de los menores o la protección de la vida privada de las partes en el proceso así lo exijan o en la medida considerada necesaria por el Tribunal, cuando en circunstancias especiales la publicidad pudiera ser perjudicial para los intereses de la justicia». 
aplicación, las garantías ofrecidas por el CEDH se aplican de manera similar en la Unión».

Lo que se pretende hacer notar en este punto es que el legislador europeo relaciona el derecho a la tutela judicial efectiva con la posibilidad de que todo tipo de asunto sea formulado ante un tribunal, sin ninguna exclusión, y no tanto con los caracteres del tribunal, la posición de las partes ante él, el modo de conducirse el proceso mediante el que alcance sus decisiones o el contenido de éstas. No significa que todos estos elementos sean indiferentes, obviamente, sino que responden a un factor algo distinto y sucesivo. Los ciudadanos tenemos derecho a dirigirnos en todo caso a un tribunal (derecho a la tutela judicial efectiva, en términos de la CDFUE y del artículo 24.1 CE, aunque como ya se ha dicho es una norma con un contenido más amplio), y, sucesivamente, a que ese tribunal, identificado con caracteres específicos, se desenvuelva de un modo concreto a través del instrumento propio de la función jurisdiccional, que es el proceso (en términos del artículo $6 \mathrm{CEDH}$, derecho a un proceso equitativo ${ }^{17}$, contenido que comparte con los incisos segundo y tercero del artículo $47 \mathrm{CDFUE}$ y con el artículo $24.2 \mathrm{CE})^{18}$.

Una aplicación práctica que me parece sumamente reveladora de la concepción del derecho a la tutela judicial efectiva mantenido por las instituciones europeas es la que hace la STJUE Unibet ${ }^{19}$. Un tribunal sueco eleva al TJUE una serie de cuestiones prejudiciales relacionadas con un procedimiento sancionador en el que se ve envuelta una empresa internacional. Y la primera de ellas se refiere a si vulnera el derecho a la tutela judicial efectiva una normativa interna que no prevé una acción directa para impugnar determinadas normas que la parte considera contrarias al Derecho Europeo, pudiendo formularse esta impugnación solo de forma incidental a través de otros procedimientos. Toda la sentencia es esclarecedora e interesante, porque explica y aplica con limpieza principios fundamentales en la interpretación europea de la tutela judicial efectiva como el de autonomía procesal de los Estados miembros ${ }^{20}$ y los de equivalencia y

17 Aunque la referencia más común en la doctrina y en la práctica sea a la formulación en inglés, Due process, o a su traducción más literal en castellano, «proceso debido».

${ }_{18}$ El esfuerzo por distinguir planos y contenidos dentro del derecho a la tutela judicial efectiva, que es necesario para que los conceptos no sean una amalgama informe sino, al contrario, instrumentos bien perfilados, no puede conducir a ignorar la relación íntima que existe entre todos ellos. En este sentido, y sobre la relación entre todos los aspectos que contempla el artículo 47 CDFUE, Triguero Martínez, 2012, 1242.

19 STJUE (Gran Sala) de 13 de marzo de 2007, Asunto C432/05 - Unibet (London) Ltd (ECLI:EU:C:2007:163). Pueden verse comentarios a esta resolución en Díez-Picazo Giménez 2008, 91-93 y Cienfuegos Mateo 2012, 458-461.

20 «Procede recordar asimismo que, ante la inexistencia de una normativa comunitaria en esta materia, corresponde al ordenamiento jurídico interno de cada Estado miembro designar los órganos jurisdiccionales competentes y configurar la regulación procesal de 
efectividad ${ }^{21}$, pero aquí es particularmente relevante la fundamentación de la decisión de la primera cuestión prejudicial: «En cualquier caso, de los apartados 56 a 61 de la presente sentencia se infiere que debe considerarse que Unibet dispone de cauces procesales que le garantizan la tutela judicial efectiva de los derechos que le confiere el ordenamiento jurídico comunitario. Si, por el contrario, como se ha señalado en el apartado 62 de la presente sentencia, tuviera que exponerse a ser objeto de procedimientos administrativos o penales, y a las sanciones que de ellos se puedan derivar, por ser éste el único cauce procesal para impugnar la conformidad de las disposiciones nacionales controvertidas con el Derecho comunitario, no quedaría suficientemente garantizada dicha tutela judicial efectiva». Dicho de otro modo, que no existan cauces para el ejercicio de acciones, aunque sean incidentales (o que los que existen impliquen el riesgo de sufrir una sanción penal o administrativa) vulnera el derecho a la tutela judicial efectiva contemplado en el artículo 47 CDFUE. Es decir, el contenido primario del artículo 47 es el derecho a tener acceso a un órgano jurisdiccional, derecho que se vulnera si el acceso es imposible o muy gravoso, porque no existe cauce procesal que lo permita o porque el que existe puede implicar consecuencias desfavorables para los ciudadanos que hagan uso de ellos ${ }^{22}$.

Ahora bien. Como se ha visto en el epígrafe anterior respecto de la configuración del derecho de acceso a los tribunales que hace nuestra jurisprudencia constitucional, el derecho a la tutela judicial efectiva no es absoluto, como ningún derecho fundamental, porque puede entrar en concurrencia con otros derechos o intereses del mismo rango, concurrencia que puede conducir a la limitación de alguno o de todos los derechos en conflicto. El TJUE define este posible conflicto en términos amplios: «No obstante, según jurisprudencia reiterada del Tribunal de Justicia, los derechos fundamentales no constituyen prerrogativas absolutas, sino que pueden ser objeto de restricciones, siempre y cuando éstas respondan efectivamente a objetivos de interés

los recursos judiciales destinados a garantizar la salvaguardia de los derechos que el Derecho comunitario confiere a los justiciables».

${ }^{21}$ « (...) la regulación procesal de las acciones destinadas a garantizar la tutela de los derechos que el ordenamiento jurídico comunitario confiere a los justiciables no debe ser menos favorable que la referente a recursos semejantes de naturaleza interna (principio de equivalencia) ni hacer imposible en la práctica o excesivamente difícil el ejercicio de los derechos conferidos por el ordenamiento jurídico comunitario (principio de efectividad) (...)».

${ }_{22}$ Por supuesto, el TJUE no ha descubierto el derecho a la tutela judicial efectiva ni la importancia del acceso a los tribunales con la CDFUE, sino que desde el comienzo de su trayectoria lo ha acogido como un principio general del Derecho comunitario, que resulta de las tradiciones constitucionales comunes a los Estados miembros y que está reconocido en el CEDH. Una mención a algunas de las SSTJUE primigenias en esta línea puede verse en Milione 2017, 661-663. 
general perseguidos por la medida en cuestión y no impliquen, habida cuenta del objetivo perseguido, una intervención desmesurada e intolerable que afecte a la propia esencia de los derechos así garantizados» ${ }^{23}$. Los parámetros para este juicio de proporcionalidad están enunciados con claridad en el artículo 52.1 CDFUE: «Cualquier limitación del ejercicio de los derechos y libertades reconocidos por la presente Carta deberá ser establecida por la ley y respetar el contenido esencial de dichos derechos y libertades. Sólo se podrán introducir limitaciones, respetando el principio de proporcionalidad, cuando sean necesarias y respondan efectivamente a objetivos de interés general reconocidos por la Unión o a la necesidad de protección de los derechos y libertades de los demás».

Aparentemente, nuestro TC formula de un modo más estricto que la CDFUE las exigencias para restringir legítimamente derechos fundamentales, aunque pienso que se trata fundamentalmente de que la jurisprudencia ofrece una regla más estructurada y desarrollada que la norma. Hay muchísimas sentencias del Tribunal Constitucional que mencionan y aplican el juicio de proporcionalidad en términos prácticamente idénticos. La STC 140/2016, de 21 de julio, que analiza entre otras muchas cuestiones la posible vulneración del derecho a la tutela judicial efectiva por una ley que impone tasas judiciales, lo expone como sigue (para agilizar la cita he suprimido la referencia a otras resoluciones del TC, pero el texto procede íntegro de la resolución citada): «Para analizar este motivo desde el prisma de la proporcionalidad que se nos solicita, hemos de partir de nuestra doctrina en torno a los presupuestos que debe cumplir toda norma con rango de ley que resulte limitadora de un derecho fundamental, los cuales son, de un lado, el consistente en perseguir una finalidad constitucionalmente legítima y, de otro, el relativo al cumplimiento del principio de proporcionalidad, cuya verificación exige, conforme a nuestra doctrina, comprobar sucesivamente el cumplimiento de los tres requisitos siguientes. En primer lugar, la medida debe ser idónea o adecuada para la consecución de los fines que persigue. En segundo lugar, la medida debe ser también necesaria, de tal manera que no resulte evidente la existencia de medidas menos restrictivas de los principios y derechos constitucionales que resultan limitados para la consecución igualmente eficaz de las finalidades deseadas por el legislador. Y, finalmente, la medida debe ser propor-

${ }^{23}$ Exposición del TJUE contenida en resoluciones como Alassini (STJUE de 18 de marzo de 2010. Asuntos C-317/08 a C-320/08 - Alassini y otros. ECLI:EU:C:2010:146); Star Storage (STJUE de 15 de septiembre de 2016. Asuntos acumulados C439/14 y C488/14 - SC Star Storage SA. ECLI:EU:C:2016:688); Menini y Rampanelli (STJUE de 14 de junio de 2017, asunto C-75/16 - Menini y Rampanelli. ECLI:EU:C:2017:457); Puskár (STJUE de 27 de septiembre de 2017. Asunto C73/16 - Puskár. ECLI:EU:C:2017:725) o Hochtief (STJUE de 7 de agosto de 2018, asunto C-300/17 - Hochtief. ECLI:EU:C:2018:635), a las que se hará referencia detallada en el epígrafe 4.3.2. 
cionada en sentido estricto, de modo que no concurra un desequilibrio patente y excesivo o irrazonable entre el alcance de la restricción de los principios y derechos constitucionales que resultan afectados, de un lado, y el grado de satisfacción de los fines perseguidos con ella por el legislador, de otro».

El único punto que podría hacer pensar que nuestro TC sostiene un canon de protección de los derechos fundamentales más elevado que el establecido por el artículo 52.1 CDFUE es la referencia a la «finalidad constitucionalmente legítima» frente a los «objetivos de interés general reconocidos por la Unión» a los que se refiere la Carta. Sin embargo, ni el TC admite únicamente la proporción con finalidades que están estrictamente descritas en la Constitución, sino también con otras muchas que pueden derivarse de sus principios estructurales y de los derechos fundamentales, ni el TJUE considera proporcional la limitación de un derecho fundamental frente a cualquier finalidad de cualquier norma de la UE.

\section{Relación entre los artículos 24.1 de la Constitución y 47 de la Carta de los Derechos Fundamentales de la Unión Europea}

No pretendo en este punto tomar parte en los debates sobre las complejas relaciones entre los ámbitos interno y europeo de aplicación de derechos fundamentales, así como entre las igualmente complejas esferas de pronunciamiento en materia de derechos fundamentales de los Tribunales Constitucionales de los Estados miembros y el Tribunal de Justicia de la Unión Europea. La pretensión de este epígrafe se ciñe únicamente a ofrecer una recapitulación de los elementos básicos de estos puntos de fricción-elementos básicos generalmente conocidos y con un grado razonable de consenso en torno a ellos-, en cuanto pueda ser útil para explicar y comprender con rigor las cuestiones que constituyen el objeto de este trabajo.

El artículo 51 CDFUE regula el ámbito de aplicación de la $\mathrm{Carta}^{24}$. Y de él se desprende que sus disposiciones se dirigen a los poderes públicos de la Unión, y también a los de los Estados miembros, siempre y cuando unos y

24 «1. Las disposiciones de la presente Carta están dirigidas a las instituciones y órganos de la Unión, respetando el principio de subsidiariedad, así como a los Estados miembros únicamente cuando apliquen el Derecho de la Unión. Por consiguiente, éstos respetarán los derechos, observarán los principios y promoverán su aplicación, con arreglo a sus respectivas competencias.

2. La presente Carta no crea ninguna competencia ni ninguna misión nuevas para la Comunidad ni para la Unión y no modifica las competencias y misiones definidas por los Tratados». 
otros apliquen el Derecho de la Unión. De esta norma se derivan dos tipos de consideraciones distintas.

- La CDFUE funciona del mismo modo que el nivel primario ${ }^{25}$ de desenvolvimiento de los derechos fundamentales de nuestra Constitución, es decir, estableciendo un círculo de protección para el individuo respecto de los poderes públicos, relacionado tanto con la incidencia directa de éstos sobre los ciudadanos (delimitan la esfera de libertad individual que el Estado tiene necesariamente que respetar) como con la actuación de los poderes públicos en el ejercicio de sus funciones, actuación que debe adoptar como criterio rector e inspirador la protección, promoción y salvaguarda de los derechos fundamentales. Dicho de otro modo, los derechos fundamentales implican para los poderes públicos tanto obligaciones de abstención o respeto como conductas activas de tutela e impulso en multitud de planos distintos.

- La aplicación del Derecho de la Unión es condición indispensable para que se apliquen a su vez los derechos de la Carta. Y, al contrario, los derechos de la Carta no rigen cuando el Derecho de la Unión no es de aplicación. Como señala Monereo Pérez ${ }^{26}$, la Carta no atribuye a la Unión la competencia de desarrollar los derechos que contiene o de legislar sobre ellos, sino que le impone la obligación de regir su actuación en el ámbito de sus competencias -un ámbito regulado siempre por el Derecho de la Unión- por el parámetro que los derechos fundamentales implican ${ }^{27}$.

Arzoz Santisteban ${ }^{28}$ pone de manifiesto que la ejecución o desarrollo por parte de los Estados miembros de los mandatos normativos de la Unión implica aplicación del Derecho de la Unión y, como consecuencia, aplicación de la CDFUE. La doctrina que se desprende de las SSTJUE

${ }_{25}$ Me refiero al plano de la mera eficacia vertical, no horizontal. Por supuesto, la eficacia horizontal existe, igual que los ciudadanos son también interlocutores directos de los derechos de la Carta y no solo beneficiarios, aunque el artículo 51 CDFUE no mencione una cosa ni la otra. En este sentido Alonso y Sarmiento 2006, 26.

${ }^{26}$ Monereo Pérez 2012, 1309-1310

27 Creo que, si bien simple, esta afirmación es cierta en sus líneas esenciales, aunque, como después diré, también pienso que el ámbito de aplicación de la Carta se extiende a través de la actuación -legítima- del Tribunal de Justicia respecto del Derecho interno de los Estados miembros. Sin embargo, hay autores que consideran que es posible que los Estados miembros estén sujetos a la aplicación de la Carta en supuestos que no implican la aplicación simultánea del Derecho de la Unión. Vid., en este sentido, Ugartemendia Eceizabarrena 2014, 907.

${ }_{28}$ Arzoz Santisteban 2015, 33-39. 
Melloni y Äkerberg-Fransson ${ }^{29}$ implica además que la aplicación de la Carta desplaza a la regulación estatal de los derechos fundamentales cuando el Derecho Europeo es exhaustivo y la armonización completa, de modo que los Estados no tienen margen para su desarrollo ${ }^{30}$; si, en cambio, la norma europea no es completa y los Estados no se limitan a trasponerla y ejecutarla sino que deben desarrollarla, la aplicación de la Carta convive con la regulación interna de los derechos fundamentales. Bien entendido, por un lado, que, puesto que el estándar mínimo es el de la CDFUE, los derechos fundamentales nacionales solo son aplicables si ofrecen un mayor nivel de protección; $y$, por otro, que incluso este mayor nivel de protección resultará improcedente si puede afectar a la efectividad, unidad y primacía del Derecho de la Unión.

Y, si éste es el ámbito de aplicación de la Carta, ¿debe preocuparse nuestro Tribunal Constitucional al pronunciarse sobre el derecho a la tutela judicial efectiva del artículo 24.1 CE por el artículo 47 CDFUE y por la interpretación que haga de él el TJUE? La respuesta es afirmativa, y en dos sentidos distintos que ya están presentes en la Declaración del TC 1/2004, de 13 de diciembre (ECLI:ES:TC:2004:1D). Por un lado, la Carta ingresa en nuestro ordenamiento con el mismo rango jurídico que los $\operatorname{Tratados}^{31}$, de modo que es predicable de ella el principio de primacía del Derecho de la Unión en su ámbito de aplicación (artículo $93 \mathrm{CE})^{32}$. Por otro lado, aun cuando ni el Derecho de la Unión ni la Carta sean aplicables, su contenido tiene valor hermenéutico a efectos del artículo 10.2 CE.

${ }^{29}$ Respectivamente, STJUE (Gran Sala) de 26 de febrero de 2013, Asunto C-399/11, Melloni (ECLI:EU:C:2013:107) y STJUE (Gran Sala) de 26 de febrero de 2013. Asunto C617/10, Äkerberg-Fransson (ECLI:EU:C:2013:105).

${ }^{30}$ Planteándose en ocasiones la situación de que la aplicación de la norma europea implica una rebaja de los niveles de protección respecto de la norma nacional, situación que está en el origen de Melloni y de otras cuestiones prejudiciales, como analiza Rodríguez-Piñero 2017 al hilo de la sentencia Taricco (STJUE de 8 de septiembre de 2015. Asunto C-105/14 - Taricco. ECLI:EU:C:2015:555).

31 Actualmente Tratado de la Unión Europea y Tratado de Funcionamiento de la Unión Europea, formulados como tales en el Tratado de Lisboa, ratificado por España mediante LO 1/2008, de 30 de julio. La declaración del TC 1/2004, de 13 de diciembre se hizo respecto del texto en el que se trabajaba entonces, el Tratado que establecía una Constitución para Europa y que no obtuvo la ratificación unánime de los Estados miembros. La Declaración, sin embargo, mantiene su validez en la medida en que se refería a disposiciones de la CDFUE, integrada entonces en el Tratado constitucional. Al rango jurídico de la Carta se refiere el artículo 6.1 TUE.

${ }^{32} \mathrm{Y}$ esto significa que, cuando concurra el ámbito de aplicación de la Carta, esta es la norma jurídica que constituye el parámetro respecto de los derechos fundamentales, incluso para el TC y desplazando la aplicación de la Constitución española, aunque la Declaración no formula de manera expresa esta conclusión. 
Por supuesto, estas posiciones no son después en la práctica tan sencillas ni tan claras ni se manifiestan en una línea recta y nítida, sino que su propia complejidad, y la que llevan en sí los supuestos concretos sobre los que se proyectan, determinan claroscuros, avances y retrocesos ${ }^{33}$. A mi juicio, para comprender la dificultad que en ocasiones parece que tiene el mismo TC para definir su posición respecto del Derecho Europeo no puede olvidarse su peculiar y específica configuración orgánica: el Tribunal Constitucional no forma parte de la jurisdicción ordinaria, y no está sometido al imperio de la ley como sí lo están los órganos jurisdiccionales que integran la jurisdicción ordinaria (artículo 117.1 CE), sino únicamente a la Constitución y a su propia Ley Orgánica (artículo 1.1 LOTC). Esta naturaleza no es casual ni caprichosa, sino la única que permite que el TC declare la ley inaplicable, en lugar de estar obligado a aplicarla. Ocurre, sin embargo, que el Derecho europeo -y la CDFUE lo es- no tiene rango de Constitución, de modo que la idea de que el TC no tiene que aplicar el Derecho de la Unión ni vigilar la aplicación que hacen de él los tribunales ordinarios, bastando que lo use como parámetro de constitucionalidad en el ámbito delos derechos fundamentales con base en el artículo 10.2 CE siempre va a encontrar un cierto apoyo y justificación.

\section{IV. ¿VULNERA LA MEDIACIÓN OBLIGATORIA EL DERECHO A LA TUTELA JUDICIAL EFECTIVA?}

\section{Derechos fundamentales y autonomía de la voluntad}

El derecho a solicitar y obtener de los tribunales una resolución sobre el fondo de un asunto es, efectivamente un derecho, y de ningún modo una obligación, de manera que los ciudadanos pueden renunciar voluntariamente al ejercicio de este derecho y no solventar su asunto o buscar otro medio de hacerlo.

Los derechos fundamentales son derechos subjetivos y, en cuanto a tales, su titular es el individuo, que puede disponer de ellos en los términos previstos por el artículo 6.2 del Código Civil, es decir, en cuanto la renuncia no perjudique a terceros ni contraríe el interés o el orden público. A mi juicio, los derechos fundamentales no admiten una renuncia genérica y absoluta (desde luego no los personalísimos, pero tampoco los de presta-

${ }^{33}$ Pueden verse en este sentido el estudio de la STC 26/2014, de 13 de febrero que hace Arzoz Santisteban 2015, 87-110, o un interesante examen de la evolución de la jurisprudencia del TC respecto de algunas cuestiones en las que está implicado el Derecho europeo en Padrós Reig 2018, 21-57. 
ción, como el derecho a la tutela judicial efectiva), pero sí es posible renunciar a ejercitarlos en supuestos $\operatorname{concretos}^{34}$.

Por esta razón, que el ordenamiento jurídico contemple medios de resolución de conflictos distintos del recurso a los tribunales es perfectamente legítimo, y no amenaza ni conculca el derecho a la tutela judicial efectiva ni la posición de la jurisdicción en la estructura del Estado social y democrático de Derecho. La determinación voluntaria del modo de proteger y defender los propios derechos e intereses -siempre que sean de naturaleza privada, como ya se ha dicho en otro punto- se relaciona con el derecho al libre desarrollo de la personalidad a que se refiere el artículo 10.2 CE y con la autonomía privada - poder de conformación de la propia esfera jurídica, en palabras de Lacruz $^{35}$ - entendida como principio general del Derecho.

La convivencia pacífica entre jurisdicción y medios alternativos de resolución de conflictos puede, en cambio, verse alterada cuando los ciudadanos son compelidos a elegir unos y abandonar otros. Por esta razón es necesario dar respuesta a la pregunta que encabeza este epígrafe: ¿se vería vulnerado el derecho a la tutela judicial efectiva por una norma que condicionase el ejercicio de un derecho ante los tribunales al sometimiento previo a un procedimiento de mediación?

\section{Mediación obligatoria, acceso a los tribunales y tutela judicial efectiva}

La necesaria trasposición de la Directiva 2008/52/CE del Parlamento Europeo y del Consejo, de 21 de mayo de 2008, sobre ciertos aspectos de la mediación en asuntos civiles y mercantiles provocó un amplio movimiento de regulación de la mediación en los Estados miembros, que tuvo como efecto que las disposiciones de la Directiva no se incorporasen a los ordenamientos internos sólo para el ámbito transfronterizo al que ésta se refería, sino también para las controversias de carácter puramente interno -posibilidad expresamente prevista, por otro lado, por el Considerando (8) de la Directiva-. Así sucedió en España con la promulgación de la Ley 5/2012, de 6 de julio, de mediación en asuntos civiles y mercantiles. Sin embargo, solo un Estado, Italia, desarrolla el camino abierto por la Directiva en el sentido de establecer la obligatoriedad de procedimientos de mediación en determinados $\operatorname{casos}^{36}$.

${ }^{34}$ No es una cuestión nada pacífica. La abordan con claridad y brevedad, aunque contienen afirmaciones que comparto y otras con las que discrepo, Díez-Picazo Giménez 2001, 133-138 y Cano Martínez de Velasco 1986, 88-98.

${ }^{35}$ Lacruz Berdejo et al. 2000, 125-131.

${ }^{36}$ En España llegó a estar previsto por el Anteproyecto de la actual Ley de Mediación, y hay otros Estados europeos que prevén mediaciones obligatorias, aunque muy concretas 
La propia Directiva 2008/52 establece los términos en los que se entabla la relación de la mediación con la obligatoriedad o con la voluntariedad, de modo que:

- El artículo 3 a) define la mediación como «un procedimiento estructurado, sea cual sea su nombre o denominación, en el que dos o más partes en un litigio intentan voluntariamente alcanzar por sí mismas un acuerdo sobre la resolución de su litigio con la ayuda de un mediador. Este procedimiento puede ser iniciado por las partes, sugerido u ordenado por un órgano jurisdiccional o prescrito por el Derecho de un Estado miembro».

- El Considerando (13) contempla la mediación como un procedimiento voluntario «en el sentido de que las partes se responsabilizan de él y pueden organizarlo como lo deseen y darlo por terminado en cualquier momento».

- Y el Considerando (14) establece que «nada de lo dispuesto en la presente Directiva debe afectar a la legislación nacional que haga obligatorio el uso de la mediación o que la someta a incentivos o sanciones, siempre que tal legislación no impida a las partes el ejercicio de su derecho de acceso al sistema judicial».

Es una realidad que las instituciones europeas fomentan el uso de la mediación, y que el hecho de que los ordenamientos internos introduzcan procedimientos obligatorios en ámbitos regulados por Directivas es, en general, valorado positivamente. Sin embargo, y más allá del acierto o desacierto de la obligatoriedad de la mediación como instrumento de política legislativa ${ }^{37}$, interesa examinar ahora su posible conflicto con el derecho fundamental a la tutela judicial efectiva, en su vertiente de acceso a la jurisdicción.

Pese a la gran repercusión obtenida por la conocida STJUE Menini y Rampanelli, el TJUE se había pronunciado antes sobre una situación parecida y relacionada con el ordenamiento jurídico italiano mediante la Sentencia de 18 de marzo de 2010, Alassini. Con base en el artículo 34 de la

\footnotetext{
y no relacionadas con el desarrollo de esta Directiva, puesto que se circunscriben generalmente a asuntos de familia. Sobre la regulación de la mediación obligatoria en Italia y las vicisitudes de su introducción, así como con las diferentes regulaciones en otros Estados miembros pueden verse Pérez Moriones 2017, 4-6; Herrera de las Heras 2017, 13-17; y Cavuoto, 2014. Este último autor no valora positivamente la experiencia italiana; en contra, Cheliz Inglés 2018, 199-205, y también el Informe del Parlamento Europeo Rebooting the Mediation Directive: Assesing the limited impact of its implementation and proposing measures to increase the number of mediations in the EU, expuesto y analizado por Azcárraga Monzonís 2016, 103-117.
}

37 Sobre esta cuestión vid. infra epígrafe 5. 
Directiva Servicio Universal ${ }^{38}$, que ordena a los Estados miembros garantizar «la disponibilidad de procedimientos extrajudiciales transparentes, sencillos y poco onerosos para tratar litigios no resueltos que afecten a los consumidores y se refieran a asuntos regulados por la presente Directiva», el Estado Italiano reguló un procedimiento de conciliación obligatorio, que debía desarrollarse ante un organismo administrativo o ante determinados órganos jurisdiccionales. Cuestionada ante el TJUE la compatibilidad de esta normativa con el Derecho Europeo, el Tribunal establece dos niveles de análisis. En primer lugar, se pregunta si un procedimiento de mediación obligatorio es compatible con una norma europea que no establece tal obligatoriedad. Y concluye que «el artículo 34, apartado 1, de la Directiva servicio universal asigna como objetivo a los Estados miembros el establecimiento de procedimientos extrajudiciales para tratar litigios no resueltos que afecten a los consumidores y se refieran a asuntos regulados por dicha Directiva. En tales circunstancias, el hecho de que una normativa nacional, como la que es objeto del procedimiento principal, no sólo haya establecido un procedimiento de conciliación extrajudicial, sino que, además, haya dispuesto la obligatoriedad del recurso a éste, previamente al ejercicio de una acción judicial, no compromete la consecución del objetivo mencionado. Al contrario, dicha normativa, en tanto en cuanto garantiza el recurso sistemático a un procedimiento extrajudicial de resolución de litigios, tiende a reforzar el efecto útil de la Directiva servicio universal». Pese a ello, el TJUE considera que «en la medida en que la instauración de un procedimiento de tentativa de conciliación obligatoria constituye un requisito de admisibilidad de las acciones judiciales, procede examinar si es compatible con el derecho a la tutela judicial efectiva».

Cuando tiene que pronunciarse sobre el artículo 47 CDFUE, el punto de partida del TJUE se basa en que, respecto del Derecho Europeo, corresponde a los ordenamientos internos disponer los cauces procesales a través de los que los ciudadanos puedan ejercitar los derechos que las normas europeas les confieren y, en definitiva, el derecho fundamental a la tutela judicial efectiva. $\mathrm{Y}$ la adecuación de estos cauces se examina teniendo en cuenta los principios de equivalencia y efectividad ${ }^{39}$. Es cierto que una mediación obligatoria que finaliza con un acuerdo no vinculante no excluye el acceso a la jurisdicción, pero el principio de efectividad impone descartar también que la exclusión o limitación se produzcan de modo indirecto haciendo excesivamente gravoso o imposible de hecho el ejercicio de los derechos ante un tribunal. Porque,

${ }^{38}$ Directiva 2002/22/CE del Parlamento Europeo y del Consejo, de 7 de marzo de 2002 , relativa al servicio universal y los derechos de los usuarios en relación con las redes y los servicios de comunicaciones electrónicas (Directiva servicio universal).

39 A los que ya se ha hecho referencia en el epígrafe 3.3 
ciertamente, en todos los casos en los que se ha planteado la cuestión, el TJUE entiende que la introducción de una etapa no jurisdiccional previa al acceso a los tribunales implica una limitación a la tutela judicial efectiva. Los requisitos examinados por el TJUE en Alassini para considerar la conformidad de un procedimiento obligatorio previo con el derecho a la tutela judicial efectiva son finalmente los siguientes ${ }^{40}$ :

- El acuerdo que se alcance no es vinculante ${ }^{41}$.

- El procedimiento no implica un retraso sustancial a efectos del ejercicio de una acción judicial posterior.

- El procedimiento previo interrumpe la prescripción de los correspondientes derechos.

- El procedimiento previo no ocasiona gastos u ocasiona gastos escasamente significativos para las partes

- La vía electrónica no constituye el único medio de acceder a ese procedimiento previo y obligatorio.

Sobre este estado de cosas se proyectan la promulgación y necesaria trasposición de la Directiva 2013/11/UE, de 21 de mayo de 2013, relativa a la resolución alternativa de litigios en materia de consumo. Esta norma, con un ámbito de aplicación más restringido que la Directiva 2008/52, puesto que se refiere solo a ciertos litigios en materia de consumo ( vid. artículo 2), avanza decididamente en lo que respecta a las posibilidades de establecer la obligatoriedad de recurrir a un sistema alternativo de solución de conflictos, disponiendo su artículo 1 in fine que «La presente Directiva se entenderá sin perjuicio de la obligatoriedad de participar en este tipo de procedimientos prescrita en la legislación nacional, siempre que esta no impida a las partes ejercer su derecho de acceso al sistema judicial». Y, de nuevo, un órgano jurisdiccional italiano suscita una cuestión prejudicial relacionada con la conformidad entre su legislación sobre mediación obligatoria y las Directivas 2013/11 y 2008/52, a la que el TJUE responde con la STJUE Menini y Rampanelli.

${ }^{40}$ Un comentario de estos requisitos puede verse en Buhígues Iglesias y Calderón Cuadrado 2011, 52-59.

${ }^{41}$ Como se ha dicho, Alassini se dicta respecto de un proceso de conciliación que tiene carácter institucional, distinto por tanto de la mediación que puede llevar a cabo un tercero. Las formas que pueden adoptar los procedimientos ADR son muy variadas; sin embargo, si el TJUE considera conforme a la tutela judicial efectiva un procedimiento obligatorio en el que necesariamente se alcanza un acuerdo, siempre que este no sea vinculante, con mayor razón lo hará respecto de procedimientos en los que ni siquiera es necesario alcanzar un acuerdo. De hecho, así sucede en Menini y Rampanelli, como ahora se dirá. 
La sentencia Menini confirma todos los puntos enunciados en Alassini para considerar compatible un procedimiento alternativo de resolución de conflictos preceptivo tanto con normas europeas que no establecen directamente tal obligatoriedad como con el derecho a la tutela judicial efectiva. Además, avanza en algunos puntos de importancia:

- Afirma que los pronunciamientos de Alassini son aplicables a las legislaciones nacionales que estipulen la obligatoriedad de procedimientos alternativos distintos de la conciliación.

- Considera que en los procesos de mediación desarrollados al amparo del ámbito de aplicación de la Directiva 2013/11 no puede exigirse que las partes estén asistidas por abogado. Pero, atención, porque esta incompatibilidad de la legislación italiana no se declara respecto del derecho a la tutela judicial efectiva, sino respecto de los artículos 8 y 9 de la Directiva 2013/11 que, como se ha dicho, tiene un ámbito de aplicación limitado a determinados asuntos que involucran a consumidores. El TJUE no ha declarado, pues, una relación directa entre la asistencia obligatoria de abogado para una mediación también obligatoria, cualquiera que sea su objeto, y la vulneración del derecho a la tutela judicial efectiva. Sin embargo, y atendiendo ya a los casos concretos, habría que ver si tal vulneración puede terminar produciéndose de manera indirecta por la vía de exceder de los «gastos escasamente significativos» a los que se refiere la sentencia Alassini para considerar la compatibilidad entre los procedimientos alternativos obligatorios y el derecho a la tutela judicial efectiva.

Menini se pronuncia, además, sobre un último punto, relativo a la posibilidad de retirarse del procedimiento obligatorio sin necesidad de alegar causa alguna y sin sufrir consecuencias desfavorables. Sin embargo, su respuesta a esta pregunta es confusa y pienso que, como consecuencia, no satisfactoria y no definitiva, de modo que este tipo de circunstancias se volverán a plantear sin duda ante el TJUE. En primer lugar, existe una falta de correlación real entre la pregunta y la respuesta, porque el tribunal italiano se refiere a no participar en el proceso de mediación, en el sentido de no iniciarlo, mientras que el tribunal responde a la circunstancia de no seguir participando en un procedimiento ya iniciado, de retirarse de é ${ }^{42}$. En segundo lugar, el TJUE responde

${ }^{42}$ Hasta el punto de que, en los Considerandos, el TJUE reconoce que, caso de referirse la cuestión al comienzo del procedimiento y no a la retirada de él, su posición sería distinta. Como, por otra parte, es de todo punto lógico, porque si un procedimiento se configura como obligatorio (y si esta configuración no es, como afirma el TJUE, contraria per se al derecho a la tutela judicial efectiva), lo normal es que se establezcan sanciones o 
conforme a la Directiva, y no según el derecho a la tutela judicial efectiva; creo que esto es evidente en la medida en que confirma que se opone a la Directiva no permitir que el consumidor se retire libremente, mientras que es conforme con ella no permitir la retirada del comerciante, circunstancia que, desde la perspectiva del derecho a la tutela judicial efectiva de éste, requeriría al menos un juicio de ponderación específico.

\section{La mediación obligatoria no vulnera el derecho a la tutela judicial efectiva, pero...}

A mi juicio, la posición general del TJUE en toda esta materia es correcta, y extrapolable a las situaciones equivalentes que lleguen a regularse en nuestro ordenamiento jurídico interno. Otra cosa muy distinta, y que desarrollaré en el epígrafe siguiente, es que considere que el legislador puede y debe hacer todo lo que no vulnera un derecho fundamental. Ningún sujeto ni objeto pueden quedar definitivamente excluidos de la jurisdicción, y, como ya se ha visto, son tan lesivas para el derecho fundamental las actuaciones directas en este sentido como las que por la vía indirecta de hacer muy difícil o gravoso el acceso a los tribunales terminan excluyéndolo de facto. Pero pueden resultar compatibles con el derecho fundamental exigencias que, introduciendo una actuación necesaria antes del ejercicio de las acciones ante los tribunales, protegen otros derechos o intereses de rango constitucional equivalente y suponen a la vez una razonable opción de reparación para los justiciables, siempre que no alejen ni compliquen el horizonte de la tutela judicial. Sobre todo, si la obligatoriedad consiste finalmente, como se propugna en ocasiones y como sucede en otros Estados, en acudir a una sesión informativa. Con estos parámetros, un procedimiento de mediación obligatoria puede no resultar contrario al derecho a la tutela judicial efectiva ${ }^{43}$, como resulta en nuestro ordenamiento con otras tres exigencias, muy distintas entre sí y también muy distintas a la mediación, pero observables desde este mismo prisma. Me refiero al requerimiento de pago en el proceso civil, a la obligación de agotar la vía administrativa previa para interponer recurso contencioso-administrativo y a la conciliación laboral.

En determinados casos, la Ley de Enjuiciamiento Civil exige al demandante que antes de interponer la demanda requiera de pago al deudor y

consecuencias desfavorables para quien incumple la obligación de iniciar el procedimiento, puesto que de otro modo no habría manera de asegurar la concurrencia de las partes. Cosa muy distinta es que, para preservar el derecho a la tutela judicial efectiva, no sea obligatorio para las partes mantenerse en él si, una vez iniciado, no satisface sus intereses o expectativas.

${ }^{43}$ Aunque, insisto de nuevo, eso no significa en absoluto que sea conveniente. 
acompañe a la demanda la acreditación de que el requerimiento se ha producido; la demanda será inadmitida si, tras advertir el secretario judicial la falta de requerimiento y otorgar plazo al actor para su subsanación, el plazo transcurre sin que esta actuación se haya realizado o acreditado ante el tribunal.

Haber formulado un requerimiento de pago previo a la interposición de la demanda es necesario para ejercitar acciones contra los fiadores o avalistas solidarios del arrendatario (artículo 437. $43^{\mathrm{a}}$ LEC) y acciones dirigidas a obtener la declaración de incumplimiento de contratos de venta a plazos de bienes muebles, arrendamiento financiero o arrendamiento de bienes muebles (artículo 439.4 en relación con el artículo $250.110^{\circ}$ y $11^{\circ}$, ambos LEC). Y un requerimiento de pago, efectuado por el acreedor extrajudicialmente y de forma previa a la interposición de la demanda ejecutiva o por el tribunal una vez admitida la demanda a la que no se acompañe acreditación de tal requerimiento, es imprescindible para proceder al embargo de los bienes del deudor cuando se formula demanda ejecutiva con base en títulos extrajudiciales (artículos 580 y 581 LEC) ${ }^{44}$.

El requerimiento de pago implica una exigencia que es necesario cumplir para poder instar de los tribunales la tutela de determinados derechos e intereses y, en este sentido, implica una limitación o condicionamiento para el derecho fundamental de acceso a los tribunales. Sin embargo, ni es una limitación absoluta ni hace muy difícil su ejercicio, porque en términos de tiempo y de coste económico no resulta excesivamente gravoso; y no solo le da la oportunidad al sujeto requerido de evitar el proceso, sino que esa oportunidad es valiosa para el propio requirente y para todo el sistema de administración de Justicia. El requerimiento de pago se mantiene en los límites de la norma, y no entra en los de la autonomía de la voluntad: el requirente le comunica al requerido lo que en Derecho estima que le corresponde, y su intención de ejercitar sus derechos por las vías procesales previstas para ello. Nadie ha cuestionado la compatibilidad del requerimiento de pago con el derecho a la tutela judicial efectiva.

De naturaleza y alcance muy distintos, aunque con el fondo común de requerir actuaciones previas al ejercicio de acciones ante los tribunales, es el artículo 25.1 de la Ley 29/1998, de 13 de julio, reguladora de la Jurisdicción Contencioso-administrativa, que inaugura tanto el Título dedicado al objeto del proceso como el Capítulo relativo a la actividad de la Administración que es impugnable mediante este proceso: «El recurso contencioso-administrativo

${ }^{44}$ En algunos casos el legislador regula requerimientos de pago específicos. Así, el artículo 7 del Real Decreto Legislativo 8/2004, que publica el texto refundido de la Ley sobre responsabilidad civil derivada de accidentes de circulación, en la redacción dada por la Ley 35/2015 de 22 de septiembre, establece la obligación de presentar reclamación previa frente a la aseguradora como requisito para la admisión de la demanda. 
es admisible en relación con las disposiciones de carácter general y con los actos expresos y presuntos de la Administración pública que pongan fin a la vía administrativa, ya sean definitivos o de trámite, si estos últimos deciden directa o indirectamente el fondo del asunto, determinan la imposibilidad de continuar el procedimiento, producen indefensión o perjuicio irreparable a derechos o intereses legítimos»». Quiere decirse que si el acto que el ciudadano estima lesivo de sus derechos o intereses no pone fin a la vía administrativa previa ${ }^{45}$, tendrá que realizar ante la Administración las actuaciones que para el caso concreto estén previstas en la Ley 39/2015, de 1 de octubre, del Procedimiento Administrativo Común de las Administraciones Públicas, hasta que obtenga la resolución contra la que puede interponer recurso contenciosoadministrativo ante los tribunales de este orden jurisdiccional. La obligación de agotar la vía previa es bastante más gravosa que la de remitir requerimiento de pago ${ }^{46}$, pero aun así compatible con el derecho a la tutela judicial efectiva, y así ha sido declarado expresamente por el TJUE en la sentencia Puskár, referida a «la obligación de agotar las vías de recurso administrativo disponibles», que no se opone al derecho de la Unión -en palabras de Puskár- «siempre que la regulación concreta del ejercicio de dichas vías de recurso no afecte de forma desproporcionada al derecho a la tutela judicial efectiva que recoge el propio artículo 47 de la Carta. En particular, es necesario que el agotamiento previo de esas vías de recurso no implique un retraso sustancial a efectos del ejercicio de la acción judicial, suponga la interrupción de la prescripción de los correspondientes derechos y no ocasione gastos excesivos».

La compatibilidad del artículo 47 de la Carta no se ha declarado solo respecto de procedimientos administrativos previos y obligatorios, sino también de otro tipo de procedimientos quasiadministrativos, con una naturaleza mixta entre lo administrativo y lo arbitral, en función de cómo los regulen los Estados miembros, derivados de la Directiva 89/665/CEE, referida a la coordinación de las disposiciones relativas a procedimientos de recurso en materia de contratos públicos de suministro y de obras, Lo peculiar de estos procedimientos es, no solo que hay que instarlos para obtener la declaración de que se han producido ilegalidades en la contratación (declaración que es susceptible de recurso ante un tribunal, aproximándolos así al agotamiento de la vía administrativa previa), sino que la posibilidad de hacer valer cualquier pretensión civil basada en una infracción de normas o procedimientos que regulen la adjudicación de contratos públicos está supeditada a tal declaración. Sobre este tipo de supuestos se pro-

45 Vid. artículo 114 de la Ley 39/2015, de 1 de octubre, del Procedimiento Administrativo Común de las Administraciones Públicas.

${ }_{46} \mathrm{Al}$ menos en tiempo, no necesariamente en recursos, puesto que los interesados pueden intervenir por sí mismos. Aunque en ocasiones la materia puede ser tan compleja que, no de iure pero sí de facto, requiera del auxilio de un profesional. 
nuncia la sentencia Hochtief: ante una demanda de indemnización de daños y perjuicios que alegaba un extremo no declarado por la comisión arbitral, un tribunal húngaro eleva al TJUE una cuestión prejudicial relativa a la compatibilidad con el Derecho de la Unión de una norma que condiciona el pronunciamiento de los tribunales a la previa y obligatoria intervención de esta comisión. El TJUE considera compatible con el Derecho de la Unión y con el derecho a la tutela judicial efectiva tanto la intervención previa y obligatoria de la comisión arbitral para declarar la infracción sobre la que se funda la solicitud de indemnización de daños y perjuicios como la imposibilidad de alegar ante la jurisdicción motivos que no fueron invocados en el procedimiento arbitral previo.

Hochtief se refiere de un modo muy parco al derecho a la tutela judicial efectiva; sin embargo, resulta iluminadora la comparación que contiene con una resolución anterior y dictada en un contexto similar, la STJUE de 26 de noviembre de 2015, Asunto C-166-MedEval (ECLI:EU:C:2015:779), que sí estimó que concurría una vulneración del artículo 47 CDFUE. En este caso también se cuestiona una normativa nacional que vincula el ejercicio de una demanda de daños y perjuicios ante los tribunales a la declaración previa de ilegalidad del procedimiento público de contratación por parte de un órgano no jurisdiccional y mediante un procedimiento no jurisdiccional. Sin embargo, no es este mecanismo en sí lo que se estima perturbador, sino el hecho de que la posibilidad de suscitar la cuestión sobre la ilegalidad del procedimiento (que determina, añado yo, la posibilidad posterior de ejercitar ante los tribunales una acción para la indemnización de los daños sufridos) precluye a los seis meses de la resolución de la contratación, y este plazo corre independientemente del momento en que se conoce o puede conocerse la comisión de la infracción que debe ser declarada previamente. La sentencia MedEval no se refiere directamente a la tutela judicial efectiva, pero sí a la vulneración del principio de efectividad, que se daña con regulaciones procesales que hacen imposible en la práctica o excesivamente difícil el ejercicio de los derechos conferidos por el ordenamiento jurídico de la Unión.

En la rama social del Derecho, los artículos 63 y 64 de la Ley 36/2011, de 10 de octubre, reguladora de la jurisdicción social, establecen los supuestos en los que es necesario intentar una mediación o conciliación «ante el servicio administrativo correspondiente o ante el órgano que asuma estas funciones» antes de interponer la demanda. De nuevo, no se trata de un trámite largo ni costoso, pero tiene una particularidad que lo convierte en relevante para la cuestión que nos ocupa. El artículo 33.2 del Estatuto de los Trabajadores limita la responsabilidad del Fondo de Garantía Salarial (FOGASA) en cuanto al pago de indemnizaciones por despido o extinción de contratos cuando el empresario finalmente no se hace cargo de ellas- únicamente a las que sean reconocidas «como consecuencia de sentencia, auto, acto de conciliación judicial o resolución administrativa a favor de los trabajadores a 
causa de despido», y no cuando estas indemnizaciones se hayan pactado ante un órgano no jurisdiccional. Esta distinción - muy gravosa para el trabajador que no la conoce y que confía en la ejecución o garantía de lo acordado ante un servicio administrativo de conciliación- se funda en que la conciliación judicial ofrece mayores garantías jurídicas y es más adecuada para evitar y prevenir fraudes que la conciliación administrativa. Resulta así que el legislador que con una mano propugna y fomenta la resolución extrajudicial de conflictos, con otra, y cuando se trata de la garantía económica del Estado, confía solo en la decisión adoptada por un órgano jurisdiccional ${ }^{47}$. Curioso.

Una cuestión más hay que despejar. Siendo el criterio del TJUE que un proceso obligatorio de mediación que reúna estas características no vulnera el derecho a la tutela judicial efectiva de la CDFUE, ¿podría considerar el Tribunal Constitucional que sí atenta contra el derecho a la tutela judicial efectiva del artículo 24.1 CE, si nuestro legislador introdujese uno en nuestro ordenamiento? Es una cuestión muy hipotética, porque su resolución está estrechamente vinculada a datos que no tenemos, a saber, las normas europeas implicadas y la regulación concreta del legislador español. Pero conviene recordar lo que ya se dijo en el epígrafe 4.1.4. La Carta desplaza a los derechos fundamentales cuando se aplica el Derecho de la Unión, teniendo en cuenta que esta aplicación no se refiere solo a las normas europeas, sino también a las promulgadas por el legislador interno en la medida en que no haya margen de creación normativa en la trasposición. Y cuando la norma interior desarrolla la norma comunitaria ambas regulaciones conviven, de manera que los derechos fundamentales internos son aplicables si ofrecen un mayor nivel de protección que los de la CDFUE, siempre que esta aplicación no vulnere la efectividad, unidad y primacía del Derecho de la Unión. Tres consideraciones:

- Es muy difícil que una norma interna que estableciera hoy un procedimiento de mediación obligatoria en nuestro país no esté vinculada en mayor o menor medida a una norma europea, de modo que si la vinculación es muy alta, el parámetro de tutela judicial efectiva aplicable sería el de la Carta, y no el de la CE.

- Si la norma interna fuese tan independiente de la norma europea que traspone como para tener un desarrollo propio, tal vez podría pretenderse cuestionar la obligatoriedad de la mediación con base en el derecho a la tutela judicial efectiva del artículo $24.1 \mathrm{CE}$, alegando que el canon de proporcionalidad auspiciado por el TC para admitir la

${ }^{47}$ Norma confirmada por la STJUE de 21 de febrero de 2008, Asunto C-498/2006 Robledillo Núñez (ECLI:EU:C:2008:109) y por la jurisprudencia de la Sala de lo Social del TS (entre otras, STS de 3 de octubre de 2016, ECLI:ES:TS:2016:4611). 
limitación de derechos fundamentales es más exigente que el que sostiene el TJUE, de modo que podría entenderse que dispensa mayor protección al derecho fundamental. Sin embargo -y suponiendo que la mediación obligatoria no pasase el test de constitucionalidad, cosa muy dudosa atendiendo al contenido que el TC atribuye al derecho a la tutela judicial efectiva en su vertiente de acceso a los tribunales- habría todavía que considerar si el hecho de que en el ordenamiento jurídico español, y por aplicación de nuestros derechos fundamentales resulte inconstitucional un procedimiento que es habitual en otros Estados miembros y que se desprende de la aplicación de normas europeas permitiría estimar que tal aplicación de nuestro estándar constitucional vulnera la efectividad, unidad y primacía del Derecho de la Unión, produciéndose entonces de nuevo el efecto de desplazar el canon de control de los derechos fundamentales desde la Constitución a la CDFUE.

- Si la norma interna fuese del todo ajena a cualquier norma europea, su concordancia con los derechos fundamentales se revisaría conforme a nuestra Constitución. No obstante, tal revisión no debe perder de vista el contenido de la Carta como criterio hermenéutico, con base en el artículo 10.2 CE.

\section{CONCLUSIÓN. EL DERECHO A LA TUTELA JUDICIAL EFECTIVA NO ES EL ÚNICO PARÁMETRO QUE MIDE LA CONVENIENCIA DE UNA MEDIACIÓN OBLIGATORIA}

Como se ha puesto de manifiesto en el epígrafe anterior, una mediación obligatoria que no implique retrasos ni costes considerables y que permita que las partes pongan fin al procedimiento cuando lo estimen oportuno, sin tener que alegar causa justificada alguna, no vulnera el derecho a la tutela judicial efectiva en su vertiente de acceso a los tribunales. No comparto, pues el que podría ser, por escala jurídica de valores, el principal argumento contra la mediación obligatoria.

Sin embargo, creo que el hecho de no ser inconstitucional no convierte en bondadosa cualquier regulación jurídica. En un Estado social y democrático de Derecho el límite de la autonomía privada y de la libertad personal del individuo (en el sentido ya aludido de poder de configuración de la propia esfera jurídica) está en el respeto de los derechos de los demás, en la protección de los débiles y de las minorías y en la preservación del bien común. El legislador debe, pues, establecer como obligatorias para los ciudadanos las conductas que puedan incardinarse en alguno de estos ámbitos, y permitir que se autodeterminen en lo demás. 
Puede pensarse que el Estado es también responsable de establecer la obligatoriedad de lo que es bueno para cada ciudadano, individualmente considerado, aunque no tenga trascendencia colectiva. Sin la extensión que tal debate requeriría, expreso sencillamente mi posición personal. Considero que esta puede resultar una óptica aceptable respecto de algunos casos concretos, normalmente relacionados con derechos fundamentales muy primarios como la vida, integridad física o salud (por ejemplo, es obligatorio llevar el cinturón de seguridad en el interior de un vehículo a motor en marcha, incluso en el caso de que se considere que no hay absolutamente nada más en riesgo que la vida del viajero). Pero creo que una formulación genérica de estas características pugna, en el ámbito jurídico, con la autonomía de la voluntad y con el libre desarrollo de la personalidad, e introduce a una sociedad en una minoría de edad perpetua que me parece poco deseable. Aun así, uno de los argumentos más extendidos a favor de la mediación obligatoria consiste en las bondades que ésta tiene para quien la utiliza, porque gana tiempo, ahorra dinero y es menos perjudicial que el proceso para la conservación de las relaciones personales ${ }^{48}$.

¿Forma parte la obligación de negociar sobre los propios asuntos antes de someterlos a un tribunal del respeto a los derechos de terceros, de la protección de colectivos desfavorecidos o minoritarios o del bien común? En general, la respuesta que recibiría esta pregunta es afirmativa. Se piensa abrumadora-

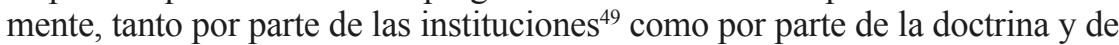
los propios tribunales ${ }^{50}$, que los medios alternativos de resolución de conflictos son un alivio para la carga de trabajo que sufren los órganos jurisdiccionales, y que existe un interés general y objetivo en fomentar medios de resolución de conflicto alternativos al recurso a la jurisdicción.

${ }^{48}$ Herrera de las Heras 2017, 9-11, con cita de otras opiniones e informes en el mismo sentido.

49 Pueden verse en este sentido y a modo de ejemplo los Considerandos de las Directivas 2008/52 y 20013/11, y el Preámbulo de nuestra Ley de Mediación.

${ }^{50}$ El AJPI Granada de 11 de noviembre de 2015 (ECLI:ES:JPI:2015:19A), recaído en autos sobre un juicio verbal de reclamación de cantidad, deja en suspenso la admisión a trámite de la demanda y convoca a las partes a una sesión informativa de mediación, para la que deben pedir cita en los diez días siguientes a la resolución. El tribunal considera que en el caso de la cantidad reclamada, 59,19 $€$, no acudir inicialmente a recursos menos costosos y congestionados implica un abuso del proceso. Cita en apoyo de su decisión el principio de la buena fe respecto del ejercicio de los derechos, criterios de ética y responsabilidad social y los artículos 440.1 y 443 LEC que, si bien se refieren a la conjunción de la mediación y el proceso civil, lo hacen respecto de la regulación de la vista y no de la admisión de la demanda. Luquin Bergareche 2017, epígrafe II.2 del texto en formato electrónico, considera que tal vez los problemas que la obligatoriedad suscita cuando se prevé en la norma jurídica (automatismo, dilación, desinterés) podrían soslayarse si la derivación no es normativa sino judicial. En un sentido similar, González Martín 2017, 127-132. 
Sin embargo, la idea de que es un fundamento adecuado para la obligatoriedad de la mediación lo mucho que descongestionaría la labor de los órganos jurisdiccionales me parece discutible, por extendido que esté el acuerdo que concita. El Estado es el responsable del funcionamiento fluido de la administración de Justicia; y no solo en el sentido de destinarle recursos materiales y personales, que desde luego también, sino desplegando creatividad (que, para que sea buena y útil, se apoya en mucho trabajo y mucho estudio) tanto en el diseño de procesos y actuaciones jurisdiccionales más adecuados para las necesidades que se detectan como para impedir el acceso al proceso o para expulsar de él lo que pueda calificarse como fraude o abuso $^{51}$. En ello está implicado, no solo un derecho fundamental de los ciudadanos, sino la propia supervivencia del Estado, que ha adquirido el monopolio de la administración de Justicia y de la coerción a cambio del derecho subjetivo público que tenemos los ciudadanos frente al Estado-juez de obtener tutela cuando la pedimos.

Los tribunales son, en ocasiones, más creativos que el legislador, con el problema, cuando la creatividad se extralimita aunque sea necesaria, de que sus decisiones no son fuente del Derecho en nuestro sistema jurídico. Un ejemplo interesante lo constituye la SAP Barcelona 231/2017, de 2 de marzo (ECLI:ES:APB:2017:4500). Se trata de una sentencia de apelación recaída en los autos de un juicio verbal relacionado con el régimen de visitas de un abuelo. La sentencia de primera instancia rechazó instaurar tal régimen considerando que concurría justa causa para ello, con base en la mala relación entre el abuelo y los progenitores de los niños. Impugnada ésta, la Audiencia considera que no existen circunstancias jurídicas valorables en el asunto, sino únicamente un conflicto entre adultos, de modo que se revoca la sentencia de instancia y se deriva el asunto a mediación, estableciéndose un régimen mínimo de visitas que solo será operativo en defecto de acuerdo. Aunque se alude a la legislación general sobre mediación, tanto estatal como promulgada por el Parlamento de Cataluña, no se citan normas específicas en apoyo del fallo.

El argumento consistente en que una de las mejores cosas que puede hacer el Estado para que funcione adecuadamente aquello que está en su propia esencia mantener, la administración de Justicia, es precisamente obligar a los ciudadanos a que traten de evitarla, me parece una falacia. Y una falacia no neutra, no inocua, sino potencialmente dañina. Porque en la medida en que el Estado asuma protagonismo respecto de esta forma alternativa de resolver conflictos -si convierte en obligatorio su uso- la coherencia impondrá que se comprometa con su sostenibilidad en coste y agilidad, de

${ }^{51}$ Mejías Gómez 2009, 59-63, hace un interesante análisis de conductas viciadas de los ciudadanos con relación al proceso. 
modo que tendrá que comenzar a dedicarle recursos de todo tipo ${ }^{52}$. Es posible pensar que no pasa nada porque las opciones para los ciudadanos se amplíen y diversifiquen, y que con ellas se diversifique también el sistema de administración de Justicia. Es posible considerarlo, incluso, muy positivo. Sin embargo, entiendo que la obligación del Estado no es mantener un sistema de justicia cualquiera, sino uno específico, que está en la Constitución y que se caracteriza por dos elementos: que se funda exclusivamente en la norma jurídica y que ésta es aplicada por órganos independientes servidos por profesionales independientes. Los ciudadanos no tenemos derecho, y un derecho fundamental, a exigir del Estado cualquier forma de tutela, sino a una muy concreta, a una tutela judicial. Y no por casualidad, sino porque precisamente esos dos caracteres son los que garantizan, en la medida en que la falibilidad humana lo permite, que se administre Justicia, una aspiración que ningún Estado debe rebajar.

Desde esta perspectiva, no estoy de acuerdo en el desplazamiento de la tutela judicial efectiva a la «tutela efectiva de la Justicia» que propugnan algunos autores, y que desemboca en la formulación de un sistema de Justicia que integra a la jurisdicción y a los medios de resolución alternativa de conflictos $^{53}$. Ya me referí en el epígrafe 2 a mi concepción sobre la relación entre la jurisdicción y los medios extrajudiciales de resolución de conflictos, y reitero ahora mi idea de que resolver conflictos no es hacer Justicia, sino alcanzar acuerdos sobre derechos e intereses particulares. Y esto está muy bien, es muy necesario y hay que fomentarlo y extenderlo, pero teniendo conceptualmente claro que la Justicia no necesita de la autonomía de la voluntad, pero los acuerdos sí (por eso es posible una opinión muy favorable hacia la mediación pero muy contraria a su obligatoriedad, como la que sostengo), y que el Estado debe garantizar como derecho fundamental, no cualquier tutela ni cualquier Justicia, sino las que se desprenden de la aplicación de la norma jurídica por órganos jurisdiccionales ${ }^{54}$.

A esta visión tan rotunda (no por la contundencia de sus argumentos, eso lo juzgará cada uno, sino por la apelación a la estructura y función del Estado) puede oponerse otra, en cambio, muy soft: bueno, no es para tanto, se trata solo de obligar a las partes a acudir a una sesión informativa, o a una primera sesión, pero no más; transcurrida esta, si no les conviene, pueden abandonar el procedimiento de mediación y dirigirse a los tribunales.

52 Barona Vilar 2016, 54-56.

53 Martín Diz 2014. 161-176 y 2014(2), 83-98. Sí comparto, en cambio, el análisis de las posibilidades de la mediación que hace este autor en Martín Diz 2017, 235-241.

${ }^{54}$ Por estas razones tampoco comparto que el derecho a la tutela judicial efectiva pueda comprenderse como un derecho a la tutela de los derechos y libertades por parte de cualquier poder público y de los institutos dedicados a la resolución alternativa de conflictos, como propone Mejías Gómez 2009, 66. 
También en las resoluciones judiciales se encuentra este planteamiento. Puede verse, por ejemplo, el AJPI Alicante de 2 de febrero de 2017 (ECLI:ES:JPI:2017:33 A A). Formuladas demanda y contestación relativas a la modificación de medidas respecto de hijos menores derivadas de un proceso contencioso, el tribunal cita a las partes de manera obligatoria a una sesión informativa de mediación -con determinación de día, hora y lugar- «tras la cual podrán voluntariamente decidir el inicio del proceso de mediación». La resolución no menciona más norma en su apoyo que el artículo $158 \mathrm{CC}$ (que no alude a la mediación, sino que es la norma sustantiva que regula el contenido de ciertas medidas relacionadas con la patria potestad), y se refiere genéricamente a la normativa estatal y autonómica sobre la mediación.

A quienes tengan una cierta edad no les resultará difícil recordar un trámite de conciliación previa, tan infructuoso y desacreditado que desapareció hace décadas de la regulación de la Ley de Enjuiciamiento Civil, pese a que se fundaba en argumentos parecidos. Precisamente porque la cultura de la negociación -y lo que lleva en sí aparejada sobre la idea de una sociedad propensa al diálogo, a la sencillez y a los acuerdos- merece respeto, y precisamente porque es necesario introducirla en nuestra sociedad, tan tendente a veces a lo contrario, no considero la mejor opción identificarla con una parodia que necesariamente hay que atravesar para llegar a donde libremente se quiere ir. Hay otras medidas de fomento de estos planteamientos, que es urgente desarrollar, algunas de ellas en marcha: la existencia de alumnos mediadores en los colegios para resolver conflictos escolares; la formación de los estudiantes de Derecho en modos alternativos de protección de los derechos e intereses de quienes en el futuro acudan a ellos; la implicación de distintas administraciones públicas en la oferta de puntos de encuentro e iniciativas similares; el reforzamiento deontológico del ejercicio de la abogacía. Tampoco sería desdeñable que los poderes públicos, en su funcionamiento interno y en la expresión de sus relaciones y modos de actuación que perciben los ciudadanos se atribuyesen una cierta función ejemplificadora en este punto. Y, en la misma línea, que se examinase con calma qué factores determinan que algo teóricamente bueno para los ciudadanos no termine de ser valorado por ellos ${ }^{55}$. Por supuesto, se trata de medidas más lentas que crear una obligación, pero son más acordes con el papel que creo que le corresponde al Estado; y tienen también mayores posibilidades de producir como efecto una sociedad consciente, responsable y madura.

Hay un último aspecto que merece consideración, y es el relativo a los litigios en los que existe desequilibrio, una parte es más fuerte que otra, con lo que, teóricamente, la parte es débil sufre en mayor medida los rigores del

55 Martínez del Hoyo Clemente 2016, 1-3; Merelles Pérez 2015, 1-6. 
proceso y, al contrario, se ve beneficiada por las bondades del procedimiento de mediación. Tres observaciones hay que hacer en este punto.

- La primera, que el mejor apoyo que puede prestarle el Estado a la parte débil es, primero, una norma que proteja sus derechos y, después, un proceso ágil para tutelar esa norma si ha sido desconocida; normalmente, el modo de equilibrar la debilidad tiene que ver con la igualdad que proporciona el proceso y con la seguridad de la aplicación de la norma jurídica. El proceso es mejorable en muchos aspectos, pero es el modo más civilizado de administrar Justicia que conocemos hasta ahora, y no conviene dejarlo por imposible respecto de ciertos asuntos, sino trabajar en su perfección.

- La segunda, que la realidad es que, para proteger a una parte débil a través de una mediación obligatoria, la obligación tendría que alcanzar a algo más que a una sesión informativa o al inicio del procedimiento ${ }^{56}$, porque a la parte teóricamente fuerte le bastaría con dejar pasar esos trámites sin acuerdo. Sin embargo, obligar a una parte a aceptar el procedimiento o el acuerdo si lo quiere la otra ya nos sitúa en otro contexto, en una restricción del derecho a la tutela judicial efectiva mucho más fuerte, que habría que observar con otros parámetros.

La STC 1/2018, de 11 de enero (ECLI:ES:TC:2018:1) resuelve una cuestión de inconstitucionalidad respecto del artículo 76 e) de la Ley 50/1980, de 8 de octubre, de Contrato de Seguro, ya que esta norma permite al asegurado decidir si somete a arbitraje las controversias que surjan con el asegurador sobre el contrato de seguro de defensa jurídica, abocando por su sola voluntad al asegurador a la exclusión de la jurisdicción. El Pleno del TC considera inconstitucional la norma estimando que conculca el derecho a la tutela judicial efectiva del asegurador, mediante una sentencia a la que se formulan tres votos particulares de cuatro magistrados que consideraban procedente la desestimación de la cuestión. He dejado fuera del ámbito de este trabajo la posibilidad de que el arbitraje sea obligatorio, puesto que su naturaleza es muy diferente a la de la mediación y muy posiblemente lo sean también las consecuencias de su obligatoriedad. Pienso sin embargo, que la STC $1 / 2018$ no es particularmente acertada, y que el debate abierto, tanto en el seno del propio TC como en la comunidad jurídica, permiten considerar que la cuestión no está todavía definitivamente resuelta.

- La tercera, que no se puede olvidar que la mediación tiene por objeto alcanzar un acuerdo, y no la adecuación de la realidad a los derechos en la medida en que la norma jurídica los reconoce. Normalmente, cuando una parte débil y precisamente por el hecho de serlo, el

${ }^{56}$ Herrera de las Heras 2017, 12. 
escenario de la norma le resulta más favorable que el del acuerdo, porque en este ámbito puede verse más forzada que la otra a dar, prometer o a permitir que el contrario retenga, haciendo uso de los términos en los que el artículo 1809 CC define la transacción, «contrato por el cual las partes, dando, prometiendo o reteniendo cada una alguna cosa, evitan la provocación de un pleito o ponen término al que había comenzado».

La mediación y el proceso, en definitiva, no entran en conflicto. Al contrario, lo deseable es que ambos se fortalezcan y se desarrollen, en beneficio de los ciudadanos y de una sociedad que no sea de pensamiento o vía únicos. $\mathrm{Ni}$ siquiera la mediación configurada como obligatoria entra en conflicto con el derecho a la tutela judicial efectiva, aunque sí supone una cierta restricción que se salva dotándola de los caracteres que ya se han visto en este trabajo. Sin embargo, compeler a los ciudadanos, no ya a intentar un acuerdo de la forma que entiendan mejor, sino a entrar en un procedimiento de mediación reglado interfiere en la autonomía privada -que es, no lo olvidemos, un principio general del Derecho- sin generar a cambio un verdadero beneficio social o colectivo sino, a la larga, un perjuicio; banaliza el diálogo y el acuerdo, en la medida en puede convertirlos en un trámite burocrático que los ciudadanos observen con disgusto; y desenfoca el papel del Estado como garante del -no ya adecuado o correcto, sino ojalá excelente, sobresaliente- funcionamiento del ejercicio de la función jurisdiccional, que no es un medio de resolución de conflictos equivalente a otros sino la garantía de la primacía de la norma jurídica, elemento angular del Estado que se pretende de Derecho.

\section{BIBLIOGRAFÍA}

Alonso García, R. y Sarmiento, D. 2006. La Carta de los Derechos Fundamentales de la Unión Europea. Explicaciones, concordancias, jurisprudencia. CizurMenor: Aranzadi.

Arzoz SANTisteban, X. 2015. La tutela de los derechos fundamentales de la Unión Europea por el Tribunal Constitucional. Madrid: Instituto Nacional de Administración Pública.

AzCÁRraga Monzonís, C. 2016. «El (limitado) impacto de la Directiva sobre mediación en asuntos civiles y mercantiles y la mediación obligatoria como medida de promoción». En Mediación, arbitraje y jurisdicción en el actual paradigma de Justicia, editado por Silvia Barona Vilar. 103-117. Cizur Menor: Aranzadi.

BARONA VILAR, S. 2016. «Justicia integral y Access to Justice. Crisis y evolución del paradigma». En Mediación, arbitraje y jurisdicción en el actual paradigma de Justicia, editado por Silvia Barona Vilar. 31-56. Cizur Menor: Aranzadi.

Borrajo Iniesta, I., Díez-Picazo Giménez, I. y Fernández Farreres, G. 1995. El derecho a la tutela judicial y el recurso de amparo. Madrid: Civitas. 
Buhígues Iglesias, J.L. y CAlderón CuAdrado, M.P. 2011. «Acceso a la justicia y mediación en asuntos civiles y mercantiles. Cuatro tópicos, tres problemas y una doble precisión». En Cooperación judicial civil y penal en el nuevo escenario de Lisboa, dirigido por Coral Arangüena Fanego. 3-60. Granada: Comares.

Cano Martínez de Velasco, J.I. 1986. La renuncia a los derechos. Barcelona: Bosch.

CAvuoto, E. 2014. «La nueva mediación obligatoria en Italia». En Mediación, Justicia y Unión Europea, coordinado por Inés Celia Iglesias Canle. 299-310. Valencia: Tirant lo Blanch.

ChÉliz Inglés, C. 2018. «La UE y la armonización de la regulación en materia de mediación: ¿hacia una mediación obligatoria en todos los Estados miembros?». Revista de estudios europeos, $\mathrm{n}^{\circ}$ 71, 189-205.

Cienfuegos Mateo, M. 2012. «Derecho a la tutela judicial efectiva y a un juez imparcial». En La Carta de los Derechos Fundamentales de la Unión Europea. Materiales de innovación docente, dirigido por Juan Ignacio Ugartemendia Eceizabarrena, Sonia García Vázquez y Juana Goizueta Vértiz. Cizur Menor: Aranzadi.

CONFORTI, F. 2016. Tutela judicial efectiva y mediación de conflictos en España. Madrid: Tecnos.

De la Oliva Santos, A. 1980. Sobre el derecho a la tutela jurisdiccional. La persona ante la administración de justicia: derechos básicos. Barcelona: Bosch.

— y DíEz-Picazo Giménez, I. 1996. Tribunal Constitucional, jurisdicción ordinaria y derechos fundamentales. Madrid: MacGraw-Hill.

— Díez-Picazo Giménez, I. y Vegas Torres, J. 2016, tercera edición. Curso de Derecho Procesal Civil I. Parte general. Madrid: Editorial Universitaria Ramón Areces.

DíEZ-PicAzo GiMÉnEZ, L.M. 2001. «Nota a la renuncia sobre los derechos fundamentales» Persona y derecho: Revista de fundamentación de las Instituciones Jurídicas y de Derechos Humanos, ${ }^{\circ}$ 45. 133-138.

— 2008. «La sentencia Unibet y el principio de autonomía procesal». Noticias de la Unión Europea no 287.91-93.

-2013, $4^{\mathrm{a}}$ ed. Sistema de derechos fundamentales. Cizur Menor: Thomson-Civitas. GONZÁlez MARTín, L.A. 2017. «La mediación intrajudicial y la tutela judicial efectiva». En Estudios sobre mediación y arbitraje desde una perspectiva procesal, dirigido por Julio Sigüenza López y Gemma García-Rostán Calvín, 121-132. Cizur Menor: Aranzadi.

HerRera de LAS Heras, R. 2017. «La mediación obligatoria para determinados asuntos civiles y mercantiles». Indret, $\mathrm{n}^{\circ}$ 1/2017. 1-23.

Lacruz Berdejo, J.L., Sancho Rebullida, F. de A., Luna Serrano, A., Delgado Echeverría, J., Rivero Hernández, F. y Rams Albesa, J. 2000, 2a ed. Elementos de Derecho Civil I. Parte General. Vol. III. Derecho subjetivo. Negocio jurídico. Madrid: Dykinson.

LuQuin Bergareche, R. 2017. «La Directiva 2013/11/UE relativa a la resolución alternativa de litigios en materia de consumo: especial referencia al principio de voluntariedad de las ADR en su interpretación por la STJUE de 14 de junio de 2017». Revista Doctrinal Aranzadi Civil-Mercantil, nº 8. 
MARTín Diz, F. 2014. «Del derecho a la tutela judicial efectiva hacia el derecho a una tutela efectiva de la Justicia». Revista Europea de Derechos Fundamentales $\mathrm{n}^{\circ}$ 23. 161-176.

2014 (2). «El derecho a una tutela efectiva de la Justicia». En Derechos y libertades en la sociedad actual, dirigido por Ángela Figueruelo Burrieza. 83-98. Granada: Comares.

— 2017. «Diseccionando la mediación: ¿un futuro en términos electrónicos?». En Cuestiones actuales de Derecho Procesal, coordinado por Ana María Rodríguez Tirado. Valencia: Tirant lo Blanch. 229-268

Martínez del Hoyo Clemente, Antonio. 2016. «¿Por qué no triunfa la mediación?». Diario La Ley no 8829, de 22 de septiembre de 2016. 1-3.

MejíAs Gómez, Juan Francisco. 2009. La mediación como forma de tutela judicial efectiva. Madrid: El Derecho.

Merelles PÉrez, Manuel. 2015. «Nuevas fórmulas para fomentar la mediación». Diario La Ley $\mathrm{n}^{\circ}$ 8646, de 16 de noviembre de 2015. 1-6.

Millione, Ciro. 2017. «La interpretación del artículo 47 CDFUE como expresión de la labor hermenéutica del Tribunal de Luxemburgo en la construcción de un estándar europeo de protección de los derechos». Teoría y realidad constitucional $n^{\circ} 39.665-674$.

Monereo Pérez, José Luis. 2012. «Artículo 51. Ámbito de aplicación». En La Europa de los derechos. Estudio sistemático de la Carta de los Derechos Fundamentales de la Unión Europea, dirigido por Cristina Monereo Atienza y José Luis Monereo Pérez, 1300-1339. Granada: Comares.

Ortuño MuÑoz, Pascual José. 2017. «Perspectivas de futuro de los métodos alternativos y complementarios de resolución de conflictos». En Estudios sobre mediación y arbitraje desde una perspectiva procesal, dirigido por Julio Sigüenza López y Gemma García-Rostán Calvín, 45-66. Cizur Menor: Aranzadi.

PADRÓs REIG, Carlos. 2018. «Algunas anotaciones sobre el difícil gozne entre Justicia constitucional española y Derecho de la Unión Europea». Revista General de Derecho, $\mathrm{n}^{\mathrm{o}} 45,14-56$.

PÉREz Moriones, Aránzazu. 2017. «Mediación obligatoria previa al ejercicio de la acción judicial en litigios promovidos por consumidores: a propósito de la STJUE de 14 de junio de 2017 (Asunto C-75/16)». Diario La Ley no 9076, de 8 de noviembre de 2017. 1-10.

Rodríguez-Piñero y Bravo-Ferrer, Miguel. 2017. «Derechos fundamentales y primacía del Derecho de la Unión Europea». Diario La Ley n 9107, 27 de diciembre de 2017. 1-9.

Triguero Martínez, Luis Ángel. 2012. «Artículo 47. Derecho a la tutela judicial efectiva y a un juez imparcial». En La Europa de los derechos. Estudio sistemático de la Carta de los Derechos Fundamentales de la Unión Europea, dirigido por Cristina Monereo Atienza y José Luis Monereo Pérez, 1237-1249. Granada: Comares.

Ugartemendia EcEIZABARRenA, Juan Ignacio. 2014. «Artículo 51. Ámbito de aplicación: los sujetos obligados por la carta y los límites a su vis expansiva». En La Carta de los Derechos Fundamentales de la Unión Europea y su reflejo en el ordenamiento jurídico español, dirigido por Ixusko Ordeñana Gezuraga, 905911. Cizur Menor: Aranzadi. 


\title{
CONSIDERACIONES SOBRE LA RELACIÓN ENTRE EL DERECHO A LA TUTELA JUDICIAL EFECTIVA Y LA MEDIACIÓN OBLIGATORIA
}

\section{Considerations on the relationship between the right to effective judicial protection and the mandatory mediation}

\author{
Pilar Peiteado Mariscal \\ Universidad Complutense de Madrid (España) \\ peiteado@der.ucm.es
}

http://dx.doi.org/10.18543/ed-66(2)-2018pp283-322

\section{Copyright}

Estudios de Deusto es una revista de acceso abierto, lo que significa que es de libre acceso en su integridad. Se permite su lectura, la búsqueda, descarga, distribución y reutilización legal en cualquier tipo de soporte sólo para fines no comerciales, sin la previa autorización del editor o el autor, siempre que la obra original sea debidamente citada y cualquier cambio en el original esté claramente indicado 